\title{
Historical Exchange Rate Risk Premiums In Currency Futures Markets
}

\author{
Ahmet Can Inci, (E-mail: ainci@cob.fsu.edu), Florida State University
}

\begin{abstract}
This paper examines the historical predictive power of future spot spread in estimating currency changes. Currency futures and spot rates over the last two decades are examined. Results show that as forecast horizon of currency depreciation increases, the slope coefficients become less positive, first losing their significance, and eventually for 1-month regressions, becoming negative for the British pound, Swiss franc and Japanese yen (significantly negative for the yen) indicating risk premiums differ with forecast horizon. On the other hand, expectations hypothesis is validated when the forecast horizon is 1 day. These results hold for each decade separately, as well as the total sample. Comparison of early (1980s) and recent (1990s) periods reveals expectations hypothesis is validated in the recent period. This indicates the trend towards a more efficient market. This should not be very surprising with the introduction of round the clock electronic trading medium and reduction of transaction fees in futures markets. This also implies that the absolute value of the risk premium has decreased over the last two decades. The extreme case of forward premium puzzle in one-month forecasts diminishes in the 1990s. The results are robust to partitioning the sample period into four sub samples and separating the data based on maturity of futures contracts.
\end{abstract}

\section{Introduction}

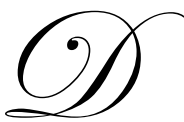

ating back to the 19th century, futures markets have expanded along with the economy beyond its agricultural roots. Two types of futures markets are available at Chicago Mercantile Exchange Inc. (CME): agricultural and financial. Financial futures at CME cover a broad array of domestic and global interest rates, currencies and indexes of stocks and commodities providing risk management tools.

As an international marketplace, CME brings together buyers and sellers on its trading floors and aroundthe-clock electronic trading platform. The exchange moves about $\$ 1.5$ billion per day in settlement payments and manages $\$ 28.2$ billion in collateral deposits. Futures on currencies are the most popular products in the international context. The world's currency markets are not the exclusive domain of the largest banks and multinational corporations. With CME currency contracts, large and small investors alike have access to the world of foreign exchange.

CME trades all major currencies ${ }^{1}$. Cross-rate contracts traded at CME used to be Euro/British pound, Euro/Japanese yen and Euro/Swiss franc and E-mini Euro and E-mini Japanese yen futures - smaller sized electronic versions of Euro FX and yen currency contracts. CME has recently launched trading in 13 new foreign exchange futures contracts ${ }^{2}$. The introduction of these futures contracts will invigorate the growth of an already fast growing futures contracts sector. Another reason that has acted as a catalyst for the growth of currency futures has been the introduction of "side-by-side" electronic and open outcry trading of CME currency and cross-rate futures contracts. CME currency futures became the first electronically traded contract after the pits on the exchange floor were closed. Electronic currency futures and pit-traded currencies both have identical contract specifications ${ }^{3}$. Another recent change has been the reduction of transaction fees. Trading volume (both in number of contracts and in total dollar amount) has been growing in recent years. Trading volume on CME rose to its highest level in the

Readers with comments or questions are encouraged to contact the author via email. 
exchange's 100 plus-year history in the beginning of 2002, with 3.6 million contracts traded on a single day with an underlying value of more than $\$ 2.6$ trillion. Underlying value of the contracts totaled nearly $\$ 30$ trillion per month. Foreign exchange futures have been setting monthly volume records consistently and these trends will continue into the future.

The analyses of futures contracts have focused on the relationship between the futures price and the current and future spot prices of the underlying commodity, currency. There are three well-established and somewhat competing theories. The first is the Expectations Hypothesis (EH from now on), which says that forward or futures rates (or prices) are unbiased estimates of expected future spot rates. The theory is tied to efficient market hypothesis and risk neutrality. If all market participants are risk neutral, they should agree on a futures price that provides an expected profit of zero to all parties, very much like market equilibrium in a world with no uncertainty. Therefore, prices follow a martingale and have a random walk nature. But forward rates may differ from expected short rates because of a risk premium (sometimes referred to as liquidity premium). EH ignores the risk premiums that must be built into futures prices when ultimate spot prices are uncertain. The second theory, normal backwardization, is based on Keynes (1930) which suggests that hedgers (or suppliers if there are more hedgers taking short positions than long based on net hedging hypothesis) would want to reduce their risk. To induce speculators to take the other position, hedgers reduce futures prices (and thus increase the returns) to profit speculators. Over time, futures prices get closer and eventually reach the spot value at maturity. The final theory, contango, is the opposite of the above: the long position holder would like to hedge (there are more hedgers with long position than short), and is willing to pay an additional premium to reduce risk. Therefore, futures price is higher than the expected future spot rate. As maturity approaches, the futures prices decrease to spot.

Hedgers and speculators take opposite positions in futures markets. They may both be net suppliers of buyers of contracts. When there is an imbalance in supply and demand, the dominant side provides incentives to the other side in the form of premiums. If the strong side is hedgers (and if they are net suppliers) who want to reduce their risk exposure, they would enter futures contacts. To induce the small number of speculators, they sell the contracts at a lower price and thus offer an additional return called risk or liquidity premium. Therefore, futures price is lower than the expected future spot value. Over time futures price gets closer to the spot value and equals at maturity. This corresponds to Keynes' normal backwardization. On the other hand, if there are more speculators than hedgers, the risk premium is now demanded by hedgers. As supplier, hedger raises futures prices due to high demand and pocket the premium between future and expected spot rate. As maturity approaches, futures value decreases and equals to spot at maturity. This is the third theory: contango.

The risk premium can be expressed as $F(t) / E_{t}\left(S_{t+\tau}\right)$, or in log form, $f_{t}-E_{t}\left(s_{t+\tau}\right)=\pi_{t+\tau}$. If the futures price is lower, risk premium is negative, indicating a wealth transfer from supply to demand (and vice versa). Dividing the numerator and denominator of the ratio by current spot value, $S_{t}$, and then taking natural logarithm leads to the following relationship:

$$
\mathrm{f}_{\mathrm{t}}-\mathrm{s}_{\mathrm{t}}=\mathrm{E}_{\mathrm{t}}\left(\mathrm{s}_{\mathrm{t}+\tau}\right)-\mathrm{s}_{\mathrm{t}}+\pi_{\mathrm{t}+\tau}
$$

where $\mathrm{f}$ is the $\log$ of futures price, $\mathrm{s}$ is the $\log$ of spot price and $\pi$ is the risk premium. If the risk premium turns out to be negative (positive), this means the second (third) theory is valid. If the risk premium is zero, then EH holds. The empirically testable version is to introduce a multiplication coefficient to the spread (difference between futures and spot values), i.e.,

$$
\mathrm{E}_{\mathrm{t}}\left(\mathrm{s}_{\mathrm{t}+\tau}\right)-\mathrm{s}_{\mathrm{t}}=\beta_{0}+\beta_{1}\left(\mathrm{f}_{\mathrm{t}}-\mathrm{s}_{\mathrm{t}}\right)+\varepsilon_{\mathrm{t}+1},
$$

where $\varepsilon$ is the error term. Under this representation, the case where $\beta_{0}=0$ and $\beta_{1}=1$ corresponds to pure EH. If $\beta_{0}$ is not 0 but constant, and $\beta_{1}=1$, then we have EH. If, on the other hand, $\beta_{1}>1(<1)$, there is a time varying risk premium. Forward price is less (higher) than the expected future spot rate, risk premium is negative (positive) in (1), and hence Keynes' normal backwardization (contango theory) holds. 
In this study I investigate how the value and sign of the slope coefficient evolves over time. In dynamic global markets and economies strong side shifts sides from demand to supply and vice versa. The goal is to determine the periods when there were more (less) demand than supply and more (less) speculators than hedgers and to offer an explanation. In other words, I try to address the questions: Why do investors choose futures markets? Is it mainly for speculative purposes or for safety? How have investors' characteristics evolved over time and why? Related to this, the study also sheds light to the following question: Do currency markets satisfy EH and risk neutrality or is there a time varying risk premium consistent with either of the two theories? The time series investigation of this study illuminates this dynamic process. The results here would constitute a stepping-stone in the development of an asset-pricing model that fits empirical observations and suggests forecast paraphernalia. These are the goals of this article.

There have been dozens of studies on the relationship between futures prices of foreign exchange contracts and the spot value of underlying currencies. The theory that has been considered most is the EH and its validity. Many studies contradict one another because of different sample periods and different estimation methodologies. The literature can be decomposed into two main categories. The first has utilized data with succinct estimation techniques ${ }^{4}$.

Hanson and Hodrick (1980) try to see if forward exchange rates are good predictors of future spot rates. The model they develop uses not only the relevant currency but also other currencies and futures data as explanatory variables. They find that the market is not efficient, i.e., futures cannot predict future exchange rates, and therefore, EH fails. Moreover, they believe this is because of a time varying risk premium with a constant component. Liu and $\mathrm{He}$ (1992) also conclude $\mathrm{EH}$ is not valid because of the existence and varying risk premiums. McCurdy and Morgan (1992) develop a theoretical model, but cannot account for all the risk premium; which they believe is the cause of the failure of EH. Sequeira, McAleer and Chow (2001) examine two models, one based on expectations hypothesis and the other on cost of carry hypothesis. Using cointegrating regressions on Australian dollar futures, they find the latter has superior empirical performance. Taylor (1992) suggests currency futures market is not even weak form efficient by providing simple but profitable technical trading strategies. On the other hand, using nonlinear dynamics Hsieh (1993) shows daily currency futures changes can be decomposed into predictable and unpredictable. Prices are not independent and identically distributed and that EH holds. Tse and Booth (1996) examine futures returns, find no autocorrelation and conclude that the market is efficient. A fundamental difference between these two studies and others is both use one-day ahead values in estimations. The other studies use one-month ahead values in the estimations. As will be shown later, this leads to significant differences. The conclusions about EH change dramatically with different lags in estimations. Overall, studies under this category generally indicate that EH does not hold. However, there are some articles which claim the opposite using different sample periods, lags, and estimation techniques.

The second category of studies has tried to develop sophisticated asset pricing models to generate closed form solutions for futures and forward prices. Using these formulas they attempt to address EH. Researchers have started with models developed to explain the term structure of interest rates ${ }^{5}$. Eventually, exclusive models such as that of Cox, Ingersoll, and Ross (1981a) enabled closed form solutions for futures contracts. Richard and Sundaresan (1981) developed a more general equilibrium model and obtained expressions for futures prices with positive or negative term premiums. Overall studies in this second category propose theoretical models that can be used for futures markets and to account for various theories, especially EH.

This paper examines currency futures using simple but effective regression models for identifiable patterns. I explain whether EH is valid or not and why. Different sample periods, different lags in forecasting regressions, and different currencies are examined. Differences of times series data are used along with ratios of time series to eliminate cointegration problem. The results show that for every currency, the slope coefficient of the regressions, $\beta_{1}$, changes over time. In the earliest periods, it is generally statistically not different from zero. But there are cases where it is significantly negative. This is defined as Forward Premium Puzzle (FPP) and was documented by Fama (1984a). Negative slope coefficients are seen if (1) the risk premium and currency change are negatively correlated and (2) risk premium has a higher variance than expected depreciation of the currency. For earlier periods, there are currencies with this trend. On the other hand, this puzzle is not seen in recent periods; slope becomes positive and 
significant, the point estimates get closer to unity satisfying EH in 1990s. This indicates investors are less risk averse and that the futures market has become efficient in late $80 \mathrm{~s}$ and early $90 \mathrm{~s}$. Recent advances of better information dissemination, round the clock electronic trading facilities, reduction in transaction costs have contributed to a more efficient foreign exchange futures market for investors, at least for longer forecast horizons. The fact that the point estimates are not exactly one is an indication that there is not perfect efficiency. Earlier periods correspond to higher futures prices, implying majority of investors were there demand such products rather than supplying them (meaning more speculators if speculators dominated demand). Premium transfer had been to supply (hedgers). Early 1980s corresponds to several recessionary periods. These and tightening of international trade with other nations (e.g., higher tariffs), strenuous relations with Japan have discouraged companies to expand their operations abroad. Revenues did not depend on foreign currency; thus there was no need to utilize currency futures on supply side. Demand side dominated supply and ended up with premiums. Late 80s and early 90 s hint that supply demand in currency futures is relatively balanced. For majority of currencies, EH holds, risk premiums are negligible. Late 90s show the effects of globalization. Many US firms have expanded overseas. Revenues depended more on foreign currency, and firms have turned to futures markets, increased supply to hedge their profits and to reduce their risk exposure. Demand (assuming net speculators, being dominated by hedgers, have been offered premiums in the form of reduced prices.

Another reason why previous studies contradicted each other was they have used different lags and time periods, some 1-day ahead, the majority 1-month ahead values in their forecasts. Using 1-day, 1 week, 2-weeks and 1-month forecast horizons, I find a clear difference in the slope coefficients across all currencies and sample periods. For the shortest forecast horizon of 1-day, the slope coefficient is almost always positive and significant. As the forecast horizon increases, the coefficient gets smaller, loses significance, and eventually becomes significantly negative in early sample periods. This reconciles some of the differences in earlier studies; forecast horizon influences the inferences drawn from their results. It also provides clear evidence of an evolving, time-varying risk premium. It seems demand side prefers longer investment horizons possibly because of transaction costs. The premium flow is from demand to supply (sign of premium is positive) for longer horizons, which indicates demand, and speculators if they characterize net demand, dominate such investments.

The rest of the paper is organized as follows: Section 2 describes the data and estimation methodology. Results are presented and discussed in Section 3. Section 4 looks at the relevance of maturity of the futures contracts and its impact on previous results. Section 5 is Summary and Conclusion.

\section{Data and Methodology}

Daily futures data are obtained from the CME through the Institute for Financial Markets (IFM), the designated distributor of daily and tick data for all futures and options contracts for the British pound (BP), German mark $(\mathrm{DM})$, Swiss franc (SF), Japanese Yen (JY), and the Euro (EC) ${ }^{6}$. Euro futures have been examined but are not reported because of the limited sample period. Although no longer traded, DM futures provide a good proxy for the Euro. A case can be made for the German mark being the dominant currency in the European Union (EU); therefore, any conclusions drawn from the mark can be considered a proxy for the behavior of Euro and Euro futures.

To construct the time series data of the futures contract, first all futures data for a particular currency were combined and sorted by quotation date. Starting with the earliest maturity data were collected up until the expiration date minus the forecast horizon. I then switched over to the next nearest maturity contract and proceeded through the most recent contract. This method has enabled to obtain a time series spanning two decades. The time series consisted of not an individual contract but a sequence of contracts. More importantly, earlier months of very small trading volume and unreliable price information in the contracts were excluded. As mentioned in Tse and Booth (1996), earlier papers have used individual contracts for their sample period. This is problematic because it is well known that currency futures are not actively traded during the first months and the settlement prices do not provide meaningful economic interpretation because of this thin trading volume. This problem can easily be demonstrated by looking at a single, representative contract and its volume of trade over the life of the contract. In Figure 1 we a typical have December 1991 futures contract for British pound. As can be seen, initially the trading volume is very small. Only after a few months, does the volume of trade pick up. In fact there are 60 trading days where the vo- 
lume of trade is less than 50 contracts for this particular futures. A similar trend can be seen for other contracts and currencies as well. Following the procedure outlined here, this problem is avoided, daily volume of trade is never less than 500 contracts for the currencies investigated here. Volume of trade of the contracts for major currencies is provided in Figure 2. There were only 7 days when the volume of trade dropped below 500 contracts for the British pound with similar results for other currency futures ${ }^{7}$.

The spot exchange rate data for the currencies are taken from Webstract, specifically, Data Resources, Inc (DRI). Exchange rate data are the average of bid and ask quotations of London Eurocurrency markets. Both futures and spot exchange rate quotations are direct, e.g., $\$ / £$ throughout the study. Descriptive information on levels of spot exchanges and futures values are provided in Table 1A. In Table 1B we have descriptive information of 1-day, 1-week, and 1-month spot returns. High volatility of currency returns compared to their means is evident from Table 1.B. This is indicative of the well-known difficulty in estimating currency returns.

Four simple regression models are constructed for the relationship between futures and expected spot values:

$$
\begin{aligned}
& \left(\mathrm{S}_{\mathrm{t}+\mathrm{FH}} / \mathrm{S}_{\mathrm{t}}-1\right)=\beta_{0}+\beta_{1}\left(\mathrm{~F}_{\mathrm{t}}-\mathrm{S}_{\mathrm{t}}\right) / \mathrm{S}_{\mathrm{t}}+\varepsilon_{\mathrm{t}+\mathrm{FH}}, \\
& \mathrm{s}_{\mathrm{t}+\mathrm{FH}}-\mathrm{s}_{\mathrm{t}}=\beta_{0}+\beta_{1}\left(\mathrm{f}_{\mathrm{t}}-\mathrm{s}_{\mathrm{t}}\right)+\mathrm{v}_{\mathrm{t}+\mathrm{FH}} \\
& \left(\mathrm{S}_{\mathrm{t}+\mathrm{FH}} / \mathrm{S}_{\mathrm{t}}-1\right)=\beta_{0}+\beta_{1}\left(\xi_{\mathrm{t}}\left(\mathrm{F}_{\mathrm{t}}-\mathrm{S}_{\mathrm{t}}\right) / \mathrm{S}_{\mathrm{t}}\right)+\varepsilon 2_{\mathrm{t}+\mathrm{FH}}, \\
& \mathrm{s}_{\mathrm{t}+\mathrm{FH}}-\mathrm{s}_{\mathrm{t}}=\beta_{0}+\beta_{1}\left(\xi_{\mathrm{t}}\left(\mathrm{f}_{\mathrm{t}}-\mathrm{s}_{\mathrm{t}}\right)\right)+v 2_{\mathrm{t}+\mathrm{FH}},
\end{aligned}
$$

where $\mathrm{S}$ is the spot exchange rate value, $\mathrm{F}$ is the futures price, $\varepsilon, v$ are error terms, and $\mathrm{FH}$ represents the forecast horizon, 1, 5, 10, 20 as the number of trading days (for one day, one week, two weeks, and one month). The first equation has spot and futures prices, the second, log of the variables and hence the difference instead of ratios. Both equations are equivalent and although results are available for both, we focus on log results.

The second pair of regressions has an additional parameter, a scaling factor as part of the independent variable. In such investigations as these, $f_{t}-s_{t}$ has been replaced with $r_{d}-r_{f}$ (which is the difference between domestic and foreign short rates) since they are supposed to be equal to each other from covered interest parity. This transformation eliminates a significant drawback. The interest rates are for the same period as the forecast horizon of the expected future spot exchange rate (generally one month) and the results are consistent. In our approach, the futures price at any time is for the period from that day until the expiration of the contract, which is generally longer than the forecast horizon. To resolve this issue, the independent variable is multiplied with a scaling factor, $\xi_{\mathrm{t}}$, which is the forecast horizon divided by the number of days to expiration. When the number of days to expiration is the same as the forecast horizon, this scaling coefficient is irrelevant but if days to expiration and forecast horizon are different, the scaling factor eliminates the discrepancy. This second set of regressions provides more accurate and correct results than the first regression pair. Both results are reported but analysis is oriented more on the second set of results. The regressions have serially correlated dependent observations leading to autocorrelated disturbances. A typical OLS regression is ideal only under a constant covariance matrix of disturbances. If disturbances are autocorrelated, as they are in our case, then one should utilize the Newey-West (1987) procedure. This is the process followed here ${ }^{8}$.

\section{Results}

The discussion of the results will be oriented towards the second set of regressions (4) with scaling coefficients. However, results of the first pair of regressions (3) are also available with some similar trends. The regression coefficients and t-statistics for different lags and currencies are presented in Table 2 for the whole sample. The results cover 1982 though 2000 for all currencies (for the British pound the results extend through the first quarter of 2000; for the German mark and Japanese yen they extend through 2001). The regression coefficients of each currency for different lags show that as forecast horizon increases, slope coefficients become less positive. They first lose their significance and for the 1-month regressions, their point estimates become negative for the British pound, Swiss franc and Japanese yen (for Japanese yen it is significantly negative). This indicates that the risk premium differs with forecast horizon. As the horizon increases, risk premiums go from demand to supply side in the market 
(speculators, assuming net demand is portrayed by them, are willing to pay premiums to avoid transactions costs by investing long term). Expectations hypothesis is more plausible when the forecast horizon is short; in fact, for the British pound when the lag is 1 day, the slope coefficient is not statistically different from one at $5 \%$ significance, which means for the whole sample period, expectations hypothesis has been valid. Furthermore, when the horizon is two-weeks, most of the coefficients are not different from 1 statistically; thus expectations hypothesis is applicable for a two-week horizon.

Overall, our investigation of futures markets for the sample period as a whole reveals that as lag of independent variable increases, slope coefficients decrease, lose their significance with respect to zero, and for the majority of the currencies become negative.

In Table 3 sample period is divided into two components and separate regressions are examined for each currency and forecast horizon. The first sub period is from 1982 to the beginning to middle of 1991 (1980s), and the second sub period covers the rest (more recent part, 1990s) of the sample. The first main conclusion is the verification of the earlier results of Table 2. As forecast horizon increases, slope coefficient decreases. If the coefficients start with a high value for the shortest lag, they first get statistically indifferent from one where EH is validated and markets are efficient (this is generally the case for the two-week horizon and to a lesser extend one-week). The slope then becomes insignificantly different from zero at longer lags. For the one-month case, point estimates are negative for most of the currencies and sub samples, indicating that the information dissemination, analysis, and interpretation occurs within one-week to two-weeks; and hence market efficiency works for these time horizons.

Comparison of the results of 1980s and 1990s reveals another pattern. The significance of the difference of slope coefficient with ' 1 ' is lower in the recent period indicating a trend to a more efficient market. Therefore, the second half of the overall sample has results more consistent with EH. For the British pound, the shorter lag coefficients are statistically close to one in the early period, while the longer lag coefficients are statistically closer to one in the more recent period. For German mark, all but the shortest lag coefficients indicate market efficiency in the recent period as opposed to the longest two lags in the early period having coefficients close to one. For Japanese yen and Swiss franc, the more recent periods provide more evidence of market efficiency; one-week and two-week results for Japan and two-week and one-month results for Switzerland indicate efficiency. The overall pattern is a movement towards a more efficient market in the more recent sub period, which also indicates that the absolute value of the risk premium decreases with time. It should also be noted that the extreme case of the FPP (negative and significant slope coefficient) seen in the one-month forecast horizon diminishes in the second sub period. For the British pound and Swiss franc, significantly negative slope coefficients become positive and insignificant in the second half. For Japanese yen the significance of the point estimate decreases while the point estimate is still negative. For German mark, the coefficient is statistically insignificant.

Next, the sample is split into 4 sample periods and regressions are conducted for each sub period, currency, and forecast horizon. The slope and intercept coefficients with t-statistics are presented in Table 4. The sample periods start with 1982 , to mid to late 1986, to beginning to mid- of 1991, to mid 1995 to early 1996 , and the rest (roughly corresponding to early and late 1980s and early and late 1990s). A finer partition such as this would make it more difficult to discern general trends; nevertheless it would provide useful results for individual currencies, the dynamics of risk premiums, validity of $\mathrm{EH}$ and market efficiency for different currencies. Also one would have a better idea about how the risk premium has evolved over the last 20 years.

As forecast horizon increases, the slope coefficient decreases for all currencies and sub periods in line with previous results. Second, FPP (significantly negative coefficients) is only seen in the very first period (early 1980s). It is a strong result because the conclusion is valid for all currencies we examine. This strong and statistically significant result might very well be the reason why studies that have included early 1980s as well as later time periods still found evidence of the FPP. We can conclude that FPP is dominant in the first half of 1980s and not seen after. Third, the longest forecast horizon of one month never has a coefficient statistically equivalent to 1 . This observation is valid for the last two sub periods of every currency as well as the second sub period for Germany and the UK. Fourth, the 2-week forecast horizon (second longest lag) does not have a significantly different coefficient with respect to 1 . The only exceptions are early 80 s and late 90 s for DM and late 90 s for the yen. 
As summary of currency futures market efficiencies, one can take sum of the number of slope coefficients based on their significance (using 5\% level). In Table 5, the numbers are obtained by adding across all currencies and relevant sample periods. In summations, 1 represents the significantly bigger slope coefficients with respect to the threshold value one; 0 insignificant, and -1 significantly less, respectively. The sum of the absolute values of the results in each row tells us how efficient the market was for that period and also tells the magnitude and sign of the risk premium. The 'Absolute Sum' column shows that late 1980s and early 1990s have indeed been more efficient than the first period. The most recent period shows evidence of a somewhat less efficient market indicating negative risk premiums indicating risk premiums going from supply side to demand. With increasing globalizations, firms' revenues depend more on foreign currency, and to reduce this risk exposure, they resort more to currency futures. These firms have increased supply of contracts and reduced their prices. Risk premiums have become larger in magnitude and negative over time and are observed for every forecast horizon. The efficiency measure in the table tells whether EH is more prevalent in certain forecast horizons. Indeed, EH varies across forecast horizons. The number of insignificant slope coefficients (i.e., EH holds) is only one when the forecast horizon is one day. For the longer horizons, this number increases dramatically; in fact when the forecast horizon is two weeks, EH cannot be rejected 13 out of 16 possible cases. One-month horizon provides evidence of EH as well since majority of the coefficients are not significantly different from the threshold value of one (10 out of 16). Finally the last column is about the FPP phenomenon. As explained before and verified in Table 5, FPP is seen mostly in the earliest period and diminishes afterwards.

Specific results for the British pound show that the slope coefficient gets bigger statistically as forecast horizon decreases, and from earlier to more recent sub samples. This trend is somewhat similar for the Swiss franc as well. For German mark the coefficients are significantly positive for the shortest two lags. The coefficient is insignificant for one-month horizon and for the middle two sub periods for the two-week horizon. All but one-day lag coefficients have moved from insignificant to significantly larger values for Japanese yen.

The common conclusion of Tables 2, 3, and 4 is that for shorter forecast horizons, the slope is positive and significant for all currencies. As a matter of fact, the FPP of previous studies is seen only in early 1980s periods for the longest horizon of 1 month. This is in agreement of those studies reporting the FPP, which have used have used 1-month forecast regressions for the currencies they examined. The results are also consistent with those of Tse and Booth (1996) and Hsieh (1993) who found evidence of EH using 1 day as the forecast horizon with recent sample periods.

Overall, the risk premium has changed significantly over time. In early 1980s futures contract holders were faced with lower rates (higher prices), i.e., positive risk premiums (going from demand to supply), which was generally the case for one-month horizons for all currencies. Late 1980s and early 1990s saw a decrease in the magnitude of the risk premium and EH could no longer be rejected for two-week to one-month investment horizons. During late 1990s the risk premium has decreased to negative amounts, which indicates forward rates (prices) have increased (decreased) compared to expected spot returns ${ }^{9}$. Thus, from suppliers' perspective premiums have become significantly negative and from demand or long position holders' perspective premiums have become significantly positive in late 1990s consistent with Keynes (1930). Although not reported here, regressions using ratios instead of log values have different slope and intercept point estimates and t-statistics but confirm the above conclusions.

\section{Does Maturity Of Futures Affect Uncovered Interest Parity And Forward Premium Puzzle?}

One of the drawbacks of previous results is that the contract maturity has not been taken into account. As maturity nears, it is natural that the risk premium decreases and spot and futures prices get close to one another. I used scaling coefficients in the regressions to eliminate this problem above. Here a different approach is followed: the sample is divided into three components based on contract maturities. For each group, the relationship between currency depreciation and futures spot difference is examined using the following regression: 


$$
s(T)-s(t)=\beta_{0}+\beta_{1}(f(t)-s(t)),
$$

where $\mathrm{s}$ is $\log$ of spot price, $\mathrm{f}$ is $\log$ of futures price of the currency, and $\mathrm{T}$ is the expiration date of the futures contract. The data is split into three parts based on the difference between the expiration date of the futures contract and current date. First group has observations with maturity of 1-day up to 1-month, the second from 1-month to 2months, and the last from 2-months to 3-months. The slope coefficients of Newey-West regressions and t-statistics are provided in Table 6. The regressions have been conducted for the whole sample as well as splitting the total sample into two components for each currency, early and late sub-periods. Finally, the entire sample period of each currency is split into four parts.

The goal is again to determine any patterns that could be identified and indeed some interesting trends can be noted from the table. Only the 2 month -3 month results had negative slope coefficients for Japanese, Swiss, and British currencies for the whole sample. The only significantly negative coefficient is the 2 month -3 month regression for Japanese yen. Moreover, for Swiss and British cases, 1 day -1 month and 1 month -2 month slope coefficients were not different from 0 and were significantly less than 1. For German and Japanese currencies, only the more distant $(1 \mathrm{~m}-2 \mathrm{~m}$ and $2 \mathrm{~m}-3 \mathrm{~m})$ cases had coefficients significantly less that 1 . Shortest maturity samples generate market efficient slope coefficients for the whole sample period. This is more pronounced in German, Swiss, and Japanese currencies. The coefficients tend to decrease from $1 \mathrm{~d}-1 \mathrm{~m}$ to $2 \mathrm{~m}-3 \mathrm{~m}$ results.

The results for the whole sample are then compared to those obtained from splitting the samples into two. For both early and late sub-periods the slope coefficient value tends to decrease from $1 \mathrm{~d}-1 \mathrm{~m}$ to $2 \mathrm{~m}-3 \mathrm{~m}$ regressions. Comparing the Early and Late periods, for British and Swiss currencies the slope coefficients are negative for the two longest maturities in 1980s (significantly negative for longest maturity). The negative coefficients tend to disappear in 1990s. As a matter of fact, for all sub-samples (1d-1m, 1m-2m, 2m-3m) the slope coefficient tends to increase with respect to the 80s. For Japan and Germany we see similar results when early and late periods are compared. Futures contract suppliers or sellers, demand higher and positive risk premiums the longer the maturity of the contract in the early period. But in 1990s suppliers prefer less risk premium in Britain, even willing to pay premiums for all maturities. For the yen and Swiss franc, supply side is willing to pay premiums for the shorter maturity contracts while for longer maturities demand dominates and premiums flow to supply.

Finally, the sample is partitioned into four sub-periods and the above regression is used for the three cases of $1 \mathrm{~d}-1 \mathrm{~m}, 1 \mathrm{~m}-2 \mathrm{~m}$, and $2 \mathrm{~m}-3 \mathrm{~m}$. A summary of the results is provided in Table 7 across currencies. The table was constructed using 5\% as the threshold significance level. For each period and maturity range, the slope coefficient is compared with the critical value of 1 (if the slope coefficient is not different from 1 statistically, there is an efficient market for that period and maturity). If the slope coefficient is significantly higher (lower) than 1, the table entry is $1(-1)$. The entries are summed across currencies to comment on the efficiency of the currency futures markets.

The markets were inefficient 11 out of the maximum of 12 cases in early 1980s. The inefficiency was clear whatever the maturity, with the only exception being the German mark. In more recent periods, the efficiency increases; in fact for late 90 s, the market is efficient 10 out of 12 cases. The most recent period is also the most efficient. The efficiency question is examined across different maturities. Shorter maturities lead to higher efficiencies. The currency market is efficient 10 out of 16 cases for $1 \mathrm{~d}-1 \mathrm{~m}$ maturity range and 11 out of 16 for $1 \mathrm{~m}-2 \mathrm{~m}$ maturity. Longest maturity has an efficiency measure of only 7 out of 16 .

Finally the age-old forward premium puzzle question; i.e., negative and significant slope coefficients is examined. The right panel of Table 7 provides clear evidence of two trends. First, forward premium puzzle is seen more clearly for longer maturity horizons, and this result is consistent with earlier results. Forward premium puzzle is not detected at all for shortest maturity. For longer maturities, the puzzle is seen in $25 \%$ of the regressions. The second trend is the dominance of the puzzle in early $80 \mathrm{~s}$. Almost half of the regressions (5 out of 12) generated significantly negative slope coefficients. This decreased to 1 in 12 for the next two sub samples (late 80s and early 90s). There is no evidence of the puzzle in the most recent period (late 90s). These results are in concert with those of Section 3. 


\section{Conclusion}

Studies on estimating currency movements have led to different conclusions. Some claim expectations hypothesis or uncovered interest parity holds, while others find no predictive power of futures spot difference in estimating the underlying currency. There is also a large body of work which documents forward premium puzzle, a negative and significant relationship in regressions of currency change on futures spot spread. This study tries to determine the historical predictive power of future spot spread. Currency futures and spot rates over the last two decades are examined. Forecasts of currency depreciation using future spot spreads show that as forecast horizon of currency depreciation increases, currency markets become inefficient for the British pound, Swiss franc and Japanese yen. This indicates risk premiums differ with forecast horizon. On the other hand, expectations hypothesis is validated for the shortest forecast horizon of 1 day. The results hold for each decade as well as the total sample.

Comparing early (1980s) and recent (1990s) periods for every currency and lag reveals that slope coefficients are statistically closer to one in the recent period validating expectations hypothesis. The trend is toward a more efficient market. This should not be very surprising with the introduction round the clock electronic trading medium and reduction of transaction fees. This also indicates that the absolute value of the risk premium decreases with time. The extreme case of forward premium puzzle seen in the one-month forecast horizon diminishes in the second sub period (1990s). The results are robust to partitioning the sample period into four sub samples and grouping the data based on maturity of futures contracts.

We can suggest some reasons why investors have preferred futures markets during the last two decades. Investors were primarily there for net speculative reasons assuming this is identified with demand in early 80s. With globalization firms have gone to currency futures and increased supply. As supply and demand for the contracts balanced, risk premiums have decreased and markets became more efficient. For some currencies, late 90s indicate an excess of supply leading to risk premiums flowing to the demand side, which is a good demonstration of the time varying nature of risk premium. It is possible that the supply demand dynamics has a cyclical but damping nature over time as markets become more efficient. Maturity of futures contracts also affects predictability and efficiency. Shorter maturities lead to more efficient markets. Recent periods are more efficient whatever the maturity range is. FPP is only seen for longest maturity contracts in early 80 s.

The results provide some important guidelines in developing an empirically valid asset-pricing model with parameters consistent with real life dynamics. First, the model must incorporate a time varying risk premium. Second, if the model is based on returns, the risk premium should be such that it should have an increasing pattern; from negative values towards positive (and vice versa is prices are used). For late 1980s and early 1990s, the risk premium should be negligible. These conclusions are valid for longer forecast horizons. For shorter horizons such as one day or one week, the risk premium is negative (i.e., hedgers, as contract holders demand a premium) and slope coefficients significantly bigger than the EH threshold of one. During late 1980s and early 1990s, the point estimates get closer to one, lose some of their significance, indicating a decreasing risk premium pattern. The conclusions presented here should become an integral part of any asset pricing model that is developed to account for the dynamics of futures and spot exchange rate markets.

\section{Endnotes}

1. Australian dollar, British pound, Brazilian real, Canadian dollar, Euro FX, French franc, Japanese yen, Mexican peso, New Zealand dollar, Russian ruble, South African rand, Swiss franc, and German mark.

2. The new contracts include 11 non-dollar cross rates and two dollar-based contracts: British Pound/Swiss Franc (BP/SF), Euro/Australian Dollar (EC/AD), British Pound/Japanese Yen (BP/JY), Euro/Canadian Dollar (EC/CD), Canadian Dollar/Japanese Yen (CD/JY), Euro/Swedish Krona (EC/SKr), Swiss Franc/Japanese Yen (SF/JY), Euro/Norwegian Krone (EC/NKr), Australian Dollar/Canadian Dollar (AD/CD), Australian Dollar/New Zealand Dollar (AD/NE), U.S. Dollar/Swedish Krona (USD/SKr), Australian Dollar/Japanese Yen (AD/JY), U.S. Dollar/Norwegian Krone (USD/NKr).

3. On CME’s GLOBEX ${ }^{\circledR} 2$ system, currency futures trade electronically virtually around the clock, from 4:30 p.m. (Central Time) to 4:00 p.m. the following business day. Open outcry trading of currencies takes place 
from 7:20 a.m. until 2:00 p.m. Monday through Friday. Daily settlement (mark to market) for each curren-

4. cy contract is to the same 2:00 p.m. price whether traded via open outcry or electronically. These estimations consider the possibility of cointegration and use of a proper regression methodology. Barkoulas, Labys, and Onochie (1999) find fractional roots in futures prices and that currency futures are cointegrated. Doukas and Rahman (1987) conduct useful and well known unit root tests based on Fuller (1976) and find clear evidence of unit roots for foreign exchange futures markets. Suggestions have been application of cointegrating regressions designed to address the long memory problem, or taking differences of the series in regressions, which have generally eliminated the unit root problem.

5. Cargill (1975), Cox, Ingersoll, and Ross (1981b), Fama (1984a), Campbell (1986), Mankiw (1986), McCulloch (1988), Richardson, Richardson, Smith (1992).

6. The data includes the price information, volume, contract name, expiration month and year of the contract. The price quotations are obtained from the trading pit at the CME. Expiration month of the contracts is based on a quarterly cycle: March, June, September, December (with H, M, U, Z as their codes). The contract names depend on the currency, month and year of expiration and whether the currency GLOBEX or pit-traded. For example a pit-traded September 2002 Japanese Yen futures are denoted by JYU02. The expiration date is the third Wednesday of these expiration months. For most currencies, the last trading day is two working days before Wednesday.

7. Not more than 4 times for German mark, Japanese yen, and Swiss franc over their respective sample periods.

8. For practical purposes if OLS was used to estimate parameters and t-values, the point estimates would be correct but t-statistics would be incorrectly higher than their Newey-West counterparts. Thus, when there are lagged observations as dependent variables, the Newey-West procedure must be followed as done here.

9. Negative premium goes from suppliers to demand side to induce them to take the opposite position. Thus premium is positive for demand side in line with Keynes (1930).

\section{References}

1. Amin, Kaushik, and R. A. Jarrow, 1991, "Pricing Foreign Currency Options Under Stochastic Interest Rates", Journal of International Money and Finance, 10.3, 310-329.

2. Backus, D., S. Foresi, and C. Telmer, 1995, "Interpreting the forward premium anomaly", Canadian Journal of Economics, 1995, S108-S119.

3. Backus, D., S. Foresi, and C. Telmer, 2001, "Affine Term Structure Models and the Forward Premium Anomaly", Journal of Finance, 56.1, 279-304.

4. Barkoulas, J. T., W. C. Labys, and J. I. Onochie, 1999, "Long Memory in Futures Prices", Financial Review, 34, 91-100.

5. Campbell, J. Y., 1986, "A Defense of Traditional Hypothesis about the Term Structure of Interest Rates", Journal of Finance, 41.4, 183-193.

6. Cargill, T. F., 1975, "The term Structure of Interest Rates: A test of the Expectations Hypothesis", Journal of Finance, 30.3, 761-771.

7. Cornell, B., and M. R. Reinganum, 1981, "Forward and Futures Prices: Evidence from the Foreign Exchange Markets", Journal of Finance, 36.12, 1035-1045.

8. Cox, J. C., J. E. Ingersoll, and S. A. Ross, 1981a, "The relation between forward prices and futures prices", Journal of Financial Economics, 9, 321-346.

9. Cox, J. C., J. E. Ingersoll, and S. A. Ross, 1981b, "A Re-examination of Traditional Hypotheses about the Term Structure of Interest Rates", Journal of Finance, 36.4, 769-799.

10. Doukas, J., and A. Rahman, 1987, "Unit Roots Tests: Evidence from the Foreign Futures Market”, Journal of Financial and Quantitative Analysis, 22.1, 101-108.

11. Fama, E. F., 1984a, "Forward and spot exchange rates", Journal of Monetary Economics, 14, 319-338.

12. Fama E. F., 1984b, "The information in the Term Structure", Journal of Financial Economics, 13, 509-528.

13. French, K. R., 1983, "A comparison of Futures and Forward Contracts", Journal of Financial Economics, $12,311-342$.

14. Fuller, W. A., 1976, Introduction to Statistical Time Series, New York, Wiley.

15. Hanson, L. P., and R. J. Hodrick, 1980, "Forward Exchange Rates as Optimal Predictors of Future Spot 
Rates: An Econometric Analysis", Journal of Political Economy, 829-853.

16. Hsieh, D. A., 1993, "Implications of Nonlinear Dynamics for Financial Risk Management", Journal of Financial and Quantitative Analysis, 28.1, 41-64.

17. Keynes, J. M., 1930, Treatise on Money, 2, 142-144.

18. [Liu, C. Y., and J. He, 1992, "Risk Premia in Foreign Currency Futures", Financial Review, 27.4, 571-587.

19. Mankiw, N. G., 1986, "The Term Structure of Interest Rates Revisited", Brookings Papers on Economic Activity, 61-96.

20. McCulloch, J. H., 1975, "The tax-adjusted yield curve”, Journal of Finance, 811-830.

21. McCurdy, T. H., and I. G. Morgan, 1992, "Single Beta Models and Currency Futures Prices", Economic Record, Supplement, 117-129.

22. Newey, W. K., and K. D. West, 1987, "A simple, positive semi-definite heteroskedastic and autocorrelation consistent covariance matrix", Econometrica, 55.3, 703-708.

23. Richard, S. F., and M. Sundaresan, 1981, "A continuous time equilibrium model of forward prices and futures prices in a multigood economy", Journal of Financial Economics, 9, 347-371.

24. Richardson, M., P. Richardson, and M. Smith, 1992, "The monotonicity of the term premium", Journal of Financial Economics, 31, 97-105.

25. Sequeira, J. M., M. McAleer, and Y. F. Chow, 2001, "Efficient Estimation and Testing of Alternative Models of Currency Futures Contracts", Economic Record, 77, 270-282.

26. Taylor, S. J., 1992, "Rewards available to currency futures speculators: Compensation for risk or evidence of inefficient pricing?", Economic Record, Supplement, 105-116.

27. Tse, Y., and G. G. Booth, 1996, "Risk Premia in Foreign Currency Futures: A Reexamination", The Financial Review, 31.3, 521-534. 
Table 1A: Descriptive Statistics of Spot Currency Levels and Futures Levels

BP: British pound, DM: German mark, JY: Japanese yen, SF: Swiss franc.

Sample period for each currency corresponds to 1982 - 2000 for British Pound and Swiss franc, 1982 - 2001 for German Mark and Japanese Yen.

\begin{tabular}{|c|c|c|c|c|}
\hline \hline Spot levels & BP & DM & JY & SF \\
\hline Mean & 1.6012 & 0.5361 & 0.0074 & 0.6431 \\
Std & 0.1587 & 0.1050 & 0.0020 & 0.1257 \\
Min & 1.0447 & 0.2889 & 0.0036 & 0.3423 \\
Max & 2.0043 & 0.7388 & 0.0123 & 0.8961 \\
Median & 1.6045 & 0.5552 & 0.0077 & 0.6682 \\
Skewness & -0.2791 & -0.4210 & -0.3468 & -0.4254 \\
Kurtosis & 3.8197 & 2.2468 & 2.2986 & 2.4506 \\
\hline \hline Futures levels & BP & DM & JY & SF \\
\hline Mean & 1.5969 & 0.5369 & 0.0074 & 0.6450 \\
Std & 0.1572 & 0.1042 & 0.0020 & 0.1252 \\
Min & 1.0500 & 0.2906 & 0.0036 & 0.3427 \\
Max & 2.0032 & 0.7413 & 0.0125 & 0.9003 \\
Median & 1.6010 & 0.5565 & 0.0077 & 0.6697 \\
Skewness & -0.3181 & -0.4228 & -0.3344 & -0.4098 \\
Kurtosis & 3.8542 & 2.2696 & 2.2976 & 2.4777 \\
\hline \hline
\end{tabular}

Table 1B: Descriptive Statistics of Spot Currency Returns

Sample period for each currency corresponds to 1982 - 2000 for British Pound and Swiss franc, 1982 - 2001 for German Mark and Japanese Yen. Spot returns are evaluated on 1-day, 1-week, and 1-month basis and raw returns are provided.

\begin{tabular}{|l|r|r|r|}
\hline \hline & \multicolumn{1}{|c|}{ 1-day } & \multicolumn{1}{c|}{ 1-week } & \multicolumn{1}{c|}{ 1-month } \\
\hline \hline A. British Pound & -0.00004 & -0.00021 & -0.00079 \\
\hline Mean & 0.00658 & 0.01527 & 0.03118 \\
Std & -0.01751 & -0.27685 & -0.05726 \\
Kkewness & 6.52772 & 6.79478 & 5.45676 \\
\hline \hline B. German Mark & & \\
\hline Mean & -0.00001 & -0.00002 & 0.00000 \\
Std & 0.00692 & 0.01574 & 0.03254 \\
Skewness & 0.18919 & 0.13933 & 0.20556 \\
Kurtosis & 5.06879 & 3.92833 & 3.11711 \\
\hline \hline C. Japanese Yen & & \\
\hline Mean & 0.00011 & 0.00059 & 0.00249 \\
Std & 0.00705 & 0.01615 & 0.03456 \\
Skewness & 0.55553 & 0.88639 & 0.57573 \\
Kurtosis & 7.47504 & 7.90690 & 4.03658 \\
\hline \hline D. Swiss Franc & & \\
\hline Mean & 0.00003 & 0.00016 & 0.00072 \\
Std & 0.00756 & 0.01718 & 0.03559 \\
Skewness & 0.21268 & 0.19292 & 0.22361 \\
Kurtosis & 4.83952 & 4.03415 & 3.15224 \\
\hline \hline
\end{tabular}


Table 2: Currency Depreciation vs. Futures Spread 1980-2000

Regression equation: $s_{t+F H}-s_{t}=\beta_{0}+\beta_{1}\left(\xi_{t}\left(f_{t}-s_{t}\right)\right)+v 2_{t+F H}$,

where $\mathrm{s}$ is $\log$ of spot price, $\mathrm{f}$ is $\log$ of futures price of the currency. Estimates and t-values for the entire sample period of each currency are provided below. FH is the forecast horizon in number of trading days. $t_{0}$ is the $t$-value of the parameter measuring the significance of its difference from $0 ; t_{1}$ is the $t$-value of the parameter measuring the significance of its difference from 1 . $\xi=$ lag/trading days to expiration is the scaling factor introduced in the second set of regressions. BP: British pound, DM: German mark, JY: Japanese yen, SF: Swiss franc. Sample periods are 1982 - 2000 BP and SF, 1982 - 2001 for DM and JY. 5\% significance levels are used for interpretation of the results.

\begin{tabular}{|c|c|c|c|c|c|c|c|c|}
\hline \hline \multicolumn{6}{|c|}{ Panel A. British Pound Regression of Currency Depreciation on Futures - Spot Spread } \\
\hline & \multicolumn{3}{|c|}{ With scaling factor $(\boldsymbol{\xi})$} & \multicolumn{3}{c|}{ Without scaling factor $(\boldsymbol{\xi} \equiv \mathbf{1})$} \\
\cline { 2 - 9 } & $\mathbf{F H = 1}$ & $\mathbf{F H = 5}$ & $\mathbf{F H = 1 0}$ & $\mathbf{F H = 2 0}$ & FH=1 & FH=5 & FH=10 & FH=20 \\
\hline $\boldsymbol{\beta}_{1}$ & 2.9248 & 2.0631 & 0.8547 & -0.2007 & 0.3915 & 0.2471 & 0.086 & -0.1864 \\
$\mathbf{t}_{\mathbf{0}}$ & 1.8656 & 6.0119 & 2.0017 & -0.3211 & 7.0199 & 2.4763 & 0.5028 & -0.6105 \\
$\mathbf{t}_{\mathbf{1}}$ & 1.2278 & 3.0979 & -0.3404 & -1.9208 & -10.9119 & -7.5466 & -5.3437 & -3.8852 \\
\hline $\boldsymbol{\beta}_{\mathbf{0}}$ & 0.0002 & 0.0006 & 0.0003 & -0.0011 & 0.001 & 0.0005 & -0.0001 & -0.0016 \\
$\mathbf{t}_{\mathbf{0}}$ & 1.2934 & 1.4339 & 0.3346 & -0.709 & 6.2545 & 1.2204 & -0.1309 & -0.9881 \\
\hline \hline
\end{tabular}

\begin{tabular}{|c|c|c|c|c|c|c|c|c|}
\hline \hline \multicolumn{6}{|c|}{ Panel B. German Mark Regression of Currency Depreciation on Futures - Spot Spread } \\
\hline & \multicolumn{3}{|c|}{ With scaling factor $(\boldsymbol{\xi})$} & \multicolumn{3}{c|}{ Without scaling factor $(\xi \equiv \mathbf{1})$} \\
\cline { 2 - 9 } & $\mathbf{F H = 1}$ & $\mathbf{F H = 5}$ & $\mathbf{F H = 1 0}$ & $\mathbf{F H = 2 0}$ & $\mathbf{F H = 1}$ & $\mathbf{F H = 5}$ & $\mathbf{F H = 1 0}$ & $\mathbf{F H = 2 0}$ \\
\hline $\boldsymbol{\beta}_{1}$ & 7.2359 & 2.5231 & 1.2794 & 0.3771 & 0.4213 & 0.3798 & 0.3401 & 0.1358 \\
$\mathbf{t}_{\mathbf{0}}$ & 10.6089 & 8.1846 & 3.1968 & 0.685 & 20.0217 & 5.3047 & 2.5865 & 0.604 \\
$\mathbf{t}_{\mathbf{1}}$ & 9.1428 & 4.9407 & 0.6982 & -1.1313 & -27.4983 & -8.6608 & -5.0185 & -3.8432 \\
\hline $\boldsymbol{\beta}_{\mathbf{0}}$ & -0.0004 & -0.0007 & -0.0007 & -0.0004 & -0.0008 & -0.0008 & -0.0008 & -0.0004 \\
$\mathbf{t}_{\mathbf{0}}$ & -3.7018 & -1.5042 & -0.7783 & -0.2212 & -7.3328 & -1.7399 & -0.8791 & -0.2121 \\
\hline \hline
\end{tabular}

\begin{tabular}{|c|c|c|c|c|c|c|c|c|}
\hline \hline \multicolumn{6}{|c|}{ Panel C. Japanese Yen Regression of Currency Depreciation on Futures - Spot Spread } \\
\hline & \multicolumn{3}{|c|}{ With scaling factor $(\xi)$} & \multicolumn{3}{c|}{ Without scaling factor $(\boldsymbol{\xi} \equiv \mathbf{1})$} \\
\cline { 2 - 9 } & $\mathbf{F H = 1}$ & $\mathbf{F H = 5}$ & $\mathbf{F H = 1 0}$ & $\mathbf{F H = 2 0}$ & FH=1 & FH=5 & FH=10 & FH=20 \\
\hline $\boldsymbol{\beta}_{1}$ & 6.2114 & 2.0552 & 0.4811 & -0.9358 & 0.3583 & 0.2177 & 0.041 & -0.3541 \\
$\mathbf{t}_{\mathbf{0}}$ & 8.008 & 5.2469 & 1.149 & -1.668 & 14.4652 & 2.9835 & 0.3391 & -1.6318 \\
$\mathbf{t}_{\mathbf{1}}$ & 6.7188 & 2.6939 & -1.2393 & -3.4503 & -25.903 & -10.7212 & -7.9298 & -6.2403 \\
\hline $\boldsymbol{\beta}_{0}$ & -0.0006 & -0.0006 & 0.0006 & 0.0048 & -0.0013 & -0.0004 & 0.001 & 0.0048 \\
$\mathbf{t}_{\mathbf{0}}$ & -4.7694 & -1.3413 & 0.6717 & 2.2365 & -10.7416 & -0.8374 & 0.9705 & 2.1965 \\
\hline \hline
\end{tabular}

\begin{tabular}{|c|c|c|c|c|c|c|c|c|}
\hline \hline \multicolumn{7}{|c|}{ Panel D. Swiss Franc Regression of Currency Depreciation on Futures - Spot Spread } \\
\hline & \multicolumn{3}{|c|}{ With scaling factor $(\boldsymbol{\xi})$} & \multicolumn{3}{c|}{ Without scaling factor $(\boldsymbol{\xi} \equiv \mathbf{1})$} \\
\cline { 2 - 9 } & $\mathbf{F H = 1}$ & $\mathbf{F H = 5}$ & $\mathbf{F H = 1 0}$ & $\mathbf{F H = 2 0}$ & $\mathbf{F H = 1}$ & $\mathbf{F H = 5}$ & $\mathbf{F H = 1 0}$ & $\mathbf{F H = 2 0}$ \\
\hline $\boldsymbol{\beta}_{1}$ & 7.0106 & 2.2249 & 0.9747 & -0.1645 & 0.3954 & 0.303 & 0.209 & -0.1093 \\
$\mathbf{t}_{\mathbf{0}}$ & 10.473 & 7.2066 & 2.5763 & -0.3104 & 19.8273 & 4.4586 & 1.6987 & -0.4882 \\
$\mathbf{t}_{\mathbf{1}}$ & 8.9791 & 3.9675 & -0.0669 & -2.1979 & -30.3147 & -10.2569 & -6.4274 & -4.9543 \\
\hline $\boldsymbol{\beta}_{\mathbf{0}}$ & -0.0006 & -0.0009 & -0.0006 & 0.001 & -0.0013 & -0.001 & -0.0005 & 0.0013 \\
$\mathbf{t}_{\mathbf{0}}$ & -5.0372 & -1.7022 & -0.562 & 0.4381 & -9.9678 & -1.7331 & -0.4859 & 0.5389 \\
\hline \hline
\end{tabular}


Table 3: Currency Depreciation vs. Futures Spread - Newey-West Regression Results for 1980s and 1990s

Regression equation: $s_{t+F H}-s_{t}=\beta_{0}+\beta_{1}\left(\xi_{t}\left(f_{t}-s_{t}\right)\right)+v 2_{t+F H}$,

where $s$ is $\log$ of spot price, $f$ is $\log$ of futures price of the currency. The entire sample period of each currency is split into two parts; an early sub period and a recent sub period. Estimates and t-values for each sub period of each currency are provided below. FH is the forecast horizon in number of trading days. $t_{0}$ is the $t$-value of the parameter measuring the significance of its difference from $0 ; t_{1}$ is the $t$-value of the parameter measuring the significance of its difference from 1 . $\xi=1$ lag/trading days to expiration is the scaling factor introduced in the second set of regressions. BP: British pound, DM: German mark, JY: Japanese yen, SF: Swiss franc. Euro results are not reported since the whole sample period for the Euro consists only of a few recent years. Early period for BP and SF is 1982 - 1991, and 1982 - mid 1991 for DM and JY. The second period is from 1991 - 2000 for BP and SF, and mid 1991 - 2001 for JY and DM. 5\% significance levels are used for interpretation of the results.

\begin{tabular}{|c|c|c|c|c|c|c|c|c|c|}
\hline \multicolumn{10}{|c|}{ Panel A. British Pound Regression of Currency Depreciation on Futures - Spot Spread } \\
\hline \multirow{7}{*}{$80 \mathrm{~s}$} & & \multicolumn{4}{|c|}{ With scaling factor $(\xi)$} & \multicolumn{4}{|c|}{ Without scaling factor $(\xi \equiv 1)$} \\
\hline & & $\mathbf{F H}=1$ & $\mathbf{F H}=\mathbf{5}$ & $\mathbf{F H}=\mathbf{1 0}$ & $\mathbf{F H}=\mathbf{2 0}$ & $\mathbf{F H}=1$ & $\mathbf{F H}=\mathbf{5}$ & $\mathbf{F H}=\mathbf{1 0}$ & $\mathbf{F H}=\mathbf{2 0}$ \\
\hline & $\beta_{1}$ & 2.3964 & 1.5609 & 0.1109 & -1.6396 & 0.3961 & 0.0610 & -0.2914 & -0.8801 \\
\hline & $\mathbf{t}_{\mathbf{0}}$ & 1.6935 & 4.0719 & 0.2623 & -2.9041 & 4.9687 & 0.7083 & -2.0871 & -3.7157 \\
\hline & $\mathbf{t}_{\mathbf{1}}$ & 0.9868 & 1.4633 & -2.1030 & -4.6754 & -7.5762 & -10.8989 & -9.2503 & -7.9375 \\
\hline & $\beta_{0}$ & 0.0002 & 0.0008 & 0.0003 & -0.0025 & 0.0012 & 0.0003 & -0.0009 & -0.0037 \\
\hline & $\mathbf{t}_{\mathbf{0}}$ & 1.2762 & 1.1628 & 0.2119 & -0.9468 & 4.6810 & 0.3924 & -0.6943 & -1.4517 \\
\hline \multirow{7}{*}{$90 \mathrm{~s}$} & & \multicolumn{4}{|c|}{ With scaling factor $(\xi)$} & \multicolumn{4}{|c|}{ Without scaling factor $(\xi \equiv 1)$} \\
\hline & & $\mathbf{F H}=1$ & $\mathbf{F H}=5$ & $\mathbf{F H}=10$ & $\mathbf{F H}=\mathbf{2 0}$ & $\mathbf{F H}=1$ & $\mathbf{F H}=5$ & $\mathbf{F H}=10$ & $\mathbf{F H}=20$ \\
\hline & $\beta_{1}$ & 7.3487 & 3.1313 & 2.5615 & 2.3307 & 0.3889 & 0.5696 & 0.7466 & 0.9933 \\
\hline & $\mathbf{t}_{\mathbf{0}}$ & 7.0170 & 4.3333 & 2.4874 & 1.7661 & 9.6682 & 2.6727 & 2.0602 & 1.5784 \\
\hline & $\mathbf{t}_{1}$ & 6.0622 & 2.9494 & 1.5163 & 1.0084 & -15.1947 & -2.0195 & -0.6994 & -0.0107 \\
\hline & $\beta_{0}$ & 0.0004 & 0.0005 & 0.0008 & 0.0014 & 0.0008 & 0.0010 & 0.0013 & 0.0018 \\
\hline & $\mathbf{t}_{0}$ & 2.8628 & 1.0742 & 0.9013 & 0.8525 & 6.5639 & 1.8278 & 1.2506 & 0.9551 \\
\hline
\end{tabular}

\begin{tabular}{|c|c|c|c|c|c|c|c|c|c|}
\hline \multicolumn{10}{|c|}{ Panel B. German Mark Regression of Currency Depreciation on Futures - Spot Spread } \\
\hline \multirow{7}{*}{ 80s } & & \multicolumn{4}{|c|}{ With scaling factor $(\xi)$} & \multicolumn{4}{|c|}{ Without scaling factor $(\xi \equiv 1)$} \\
\hline & & $\mathbf{F H}=1$ & $\mathbf{F H}=5$ & $F H=10$ & $\mathbf{F H}=\mathbf{2 0}$ & $\mathbf{F H}=1$ & $\mathbf{F H}=\mathbf{5}$ & $\mathbf{F H}=\mathbf{1 0}$ & $\mathbf{F H}=\mathbf{2 0}$ \\
\hline & $\beta_{1}$ & 7.6827 & 2.8913 & 1.5802 & 0.3008 & 0.5679 & 0.5013 & 0.4206 & 0.0532 \\
\hline & $\mathbf{t}_{\mathbf{0}}$ & 7.4051 & 8.3761 & 3.4005 & 0.3706 & 19.6299 & 5.5075 & 2.3177 & 0.1448 \\
\hline & $\mathbf{t}_{1}$ & 6.4412 & 5.4792 & 1.2485 & -0.8615 & -14.9332 & -5.4783 & -3.1930 & -2.5777 \\
\hline & $\beta_{0}$ & -0.0006 & -0.0008 & -0.0003 & 0.0020 & -0.0018 & -0.0013 & -0.0006 & 0.0023 \\
\hline & $\mathbf{t}_{\mathbf{0}}$ & -3.6897 & -1.1892 & -0.2484 & 0.6009 & -10.8381 & -1.9249 & -0.4111 & 0.6643 \\
\hline \multirow{7}{*}{$90 s$} & & \multicolumn{4}{|c|}{ With scaling factor $(\xi)$} & \multicolumn{4}{|c|}{$\begin{array}{ll}\text { Without scaling factor }(\xi \equiv 1) \\
\end{array}$} \\
\hline & & $\mathbf{F H}=1$ & $\mathbf{F H}=5$ & $\mathbf{F H}=10$ & $\mathbf{F H}=\mathbf{2 0}$ & $\mathbf{F H}=1$ & $\mathbf{F H}=5$ & $\mathbf{F H}=10$ & $\mathbf{F H}=\mathbf{2 0}$ \\
\hline & $\beta_{1}$ & 6.6816 & 1.9873 & 0.6611 & -0.1326 & 0.3190 & 0.2637 & 0.2060 & -0.0166 \\
\hline & $\mathbf{t}_{\mathbf{0}}$ & 8.0999 & 3.7802 & 1.0053 & -0.1653 & 10.2818 & 2.3941 & 1.0745 & -0.0540 \\
\hline & $\mathbf{t}_{1}$ & 6.8876 & 1.8780 & -0.5154 & -1.4119 & -21.9483 & -6.6848 & -4.1408 & -3.3053 \\
\hline & $\beta_{0}$ & -0.0002 & -0.0007 & -0.0013 & -0.0026 & -0.0002 & -0.0007 & -0.0013 & -0.0026 \\
\hline & $\mathbf{t}_{0}$ & -1.3961 & -1.2093 & -1.1414 & -1.1237 & -1.5984 & -1.1948 & -1.1520 & -1.1289 \\
\hline
\end{tabular}


Table 3 (Cont'd)

\begin{tabular}{|c|c|c|c|c|c|c|c|c|c|}
\hline \multicolumn{10}{|c|}{ Panel C. Japanese Yen Regression of Currency Depreciation on Futures - Spot Spread } \\
\hline \multirow{7}{*}{$80 \mathrm{~s}$} & & \multicolumn{4}{|c|}{ With scaling factor $(\xi)$} & \multicolumn{4}{|c|}{ Without scaling factor $(\xi \equiv 1)$} \\
\hline & & $\mathbf{F H}=\mathbf{1}$ & FH=5 & $\mathbf{F H}=\mathbf{1 0}$ & $\mathbf{F H}=\mathbf{2 0}$ & $\mathbf{F H}=1$ & FH=5 & $\mathbf{F H}=\mathbf{1 0}$ & $\mathbf{F H}=\mathbf{2 0}$ \\
\hline & $\beta_{1}$ & 5.5734 & 2.3286 & 0.8430 & -0.8929 & 0.4559 & 0.3516 & 0.1408 & -0.4546 \\
\hline & $\mathbf{t}_{\mathbf{0}}$ & 6.1923 & 5.7819 & 1.5975 & -1.1501 & 14.0501 & 3.3824 & 0.7621 & -1.3960 \\
\hline & $\mathbf{t}_{1}$ & 5.0813 & 3.2988 & -0.2975 & -2.4383 & -16.7712 & -6.2386 & -4.6520 & -4.4666 \\
\hline & $\beta_{0}$ & -0.0003 & -0.0001 & 0.0012 & 0.0062 & -0.0014 & -0.0004 & 0.0014 & 0.0068 \\
\hline & $\mathbf{t}_{\mathbf{0}}$ & -2.3688 & -0.2097 & 0.9168 & 2.0257 & -8.9429 & -0.5783 & 1.0065 & 2.1657 \\
\hline \multirow{7}{*}{$90 \mathrm{~s}$} & & \multicolumn{4}{|c|}{ With scaling factor $(\xi)$} & \multicolumn{4}{|c|}{ Without scaling factor $(\xi \equiv 1)$} \\
\hline & & $\mathbf{F H}=1$ & $\mathbf{F H}=5$ & $\mathbf{F H}=10$ & $\mathbf{F H}=20$ & $\mathbf{F H}=1$ & FH=5 & $\mathbf{F H}=10$ & $\mathbf{F H}=20$ \\
\hline & $\beta_{1}$ & 7.9030 & 1.8743 & 0.2456 & -0.8156 & 0.2820 & 0.1237 & -0.0073 & -0.2170 \\
\hline & $\mathbf{t}_{\mathbf{0}}$ & 8.0738 & 2.6118 & 0.3831 & -1.0413 & 7.4605 & 1.2004 & -0.0456 & -0.7641 \\
\hline & $\mathbf{t}_{\mathbf{1}}$ & 7.0521 & 1.2183 & -1.1767 & -2.3180 & -18.9949 & -8.5038 & -6.2682 & -4.2853 \\
\hline & $\beta_{0}$ & -0.0010 & -0.0011 & 0.0000 & 0.0030 & -0.0013 & -0.0005 & 0.0004 & 0.0023 \\
\hline & $\mathbf{t}_{0}$ & -5.3446 & -1.5996 & -0.0120 & 1.0199 & -6.3371 & -0.6661 & 0.2512 & 0.7849 \\
\hline
\end{tabular}

\begin{tabular}{|c|c|c|c|c|c|c|c|c|c|}
\hline \multicolumn{10}{|c|}{ Panel D. Swiss Franc Regression of Currency Depreciation on Futures - Spot Spread } \\
\hline \multirow{7}{*}{ 80s } & & \multicolumn{4}{|c|}{ With scaling factor $(\xi)$} & \multicolumn{4}{|c|}{ Without scaling factor $(\xi \equiv 1)$} \\
\hline & & FH=1 & $\mathbf{F H}=5$ & FH=10 & $\mathbf{F H}=\mathbf{2 0}$ & FH=1 & FH=5 & $\mathbf{F H}=10$ & $\mathbf{F H}=\mathbf{2 0}$ \\
\hline & $\beta_{1}$ & 6.8613 & 2.0729 & 0.8506 & -1.0741 & 0.4713 & 0.3253 & 0.1204 & -0.5475 \\
\hline & $\mathbf{t}_{\mathbf{0}}$ & 7.1608 & 5.8491 & 2.1218 & -2.0680 & 17.9566 & 3.7369 & 0.7927 & -2.2288 \\
\hline & $\mathbf{t}_{1}$ & 6.1172 & 3.0274 & -0.3728 & -3.9933 & -20.1460 & -7.7504 & -5.7896 & -6.2993 \\
\hline & $\beta_{0}$ & -0.0008 & -0.0007 & 0.0004 & 0.0067 & -0.0023 & -0.0011 & 0.0009 & 0.0079 \\
\hline & $\mathbf{t}_{\mathbf{0}}$ & -4.1000 & -0.8782 & 0.2615 & 2.0740 & -11.7545 & -1.2941 & 0.5386 & 2.3991 \\
\hline \multirow{7}{*}{$90 \mathrm{~s}$} & & \multicolumn{4}{|c|}{ With scaling factor $(\xi)$} & \multicolumn{4}{|c|}{ Without scaling factor $(\xi \equiv 1)$} \\
\hline & & $\mathbf{F H}=1$ & $\mathbf{F H}=5$ & $\mathbf{F H}=10$ & $\mathbf{F H}=20$ & $\mathbf{F H}=1$ & $\mathbf{F H}=5$ & $\mathbf{F H}=10$ & $\mathbf{F H}=20$ \\
\hline & $\beta_{1}$ & 7.4469 & 2.3960 & 0.8254 & 0.0609 & 0.3542 & 0.2723 & 0.2194 & 0.0286 \\
\hline & $\mathbf{t}_{\mathbf{0}}$ & 10.6188 & 4.5548 & 1.2563 & 0.0693 & 11.2753 & 2.5923 & 1.1477 & 0.0806 \\
\hline & $t_{1}$ & 9.1928 & 2.6538 & -0.2657 & -1.0687 & -20.5601 & -6.9271 & -4.0829 & -2.7410 \\
\hline & $\beta_{0}$ & -0.0004 & -0.0010 & -0.0014 & -0.0020 & -0.0006 & -0.0009 & -0.0014 & -0.0020 \\
\hline & $\mathbf{t}_{0}$ & -2.7562 & -1.4660 & -0.9570 & -0.6636 & -3.7159 & -1.2872 & -0.9761 & -0.6671 \\
\hline
\end{tabular}


Table 4: Currency Depreciation vs. Futures Spread: 4 Sub-sample Periods

Newey-West regression equation: $s_{t+F H}-s_{t}=\beta_{0}+\beta_{1}\left(\xi_{t}\left(f_{t}-s_{t}\right)\right)+v 2_{t+F H}$,

where $s$ is $\log$ of spot price, $f$ is $\log$ of futures price of the currency. The entire sample period of each currency is split into four parts. Estimates and t-values for each sub period of each currency are provided below. FH is the forecast horizon in number of trading days. $t_{0}$ is the $t$-value of the parameter measuring the significance of its difference from 0 ; $t_{1}$ is the $t$-value of the parameter measuring the significance of its difference from $1 . \xi=\mathrm{lag} /$ trading days to expiration is the scaling factor introduced in the second set of regressions. BP: British pound, DM: German mark, JY: Japanese yen, SF: Swiss franc. Euro results are not reported since the whole sample period for the Euro consists only of a few recent years.

P1 through P4 represent each of the four sub sample periods for each currency. For BP and SF they are 1982 to mid 1986 , to 1991, to end of 1995, and to 2000; for DM and JY, the sub sample periods cover 1982 to late 1986, to mid 1991 , to 1996 and to 2001. 5\% significance levels are used for interpretation of the results.

\begin{tabular}{|c|c|c|c|c|c|}
\hline \multicolumn{6}{|c|}{$\begin{array}{l}\text { Panel A. British Pound Regression of Currency } \\
\text { Depreciation on Futures - Spot Spread }\end{array}$} \\
\hline \multirow{7}{*}{$\begin{array}{c}\text { Early } \\
80 \mathrm{~s}\end{array}$} & & \multicolumn{4}{|c|}{ With scaling factor $(\xi)$} \\
\hline & & FH=1 & $\mathbf{F H}=\mathbf{5}$ & $\mathbf{F H}=10$ & $\mathbf{F H}=\mathbf{2 0}$ \\
\hline & $\beta_{1}$ & 1.7710 & 1.9121 & 0.4722 & -1.7232 \\
\hline & $\mathbf{t}_{0}$ & 1.3951 & 3.7664 & 0.7953 & -2.2525 \\
\hline & $\mathbf{t}_{1}$ & 0.6074 & 1.7966 & -0.8891 & -3.5597 \\
\hline & $\beta_{0}$ & -0.0001 & -0.0006 & -0.0018 & -0.0050 \\
\hline & $\mathbf{t}_{\mathbf{0}}$ & -0.3676 & -0.6302 & -0.9471 & -1.4530 \\
\hline \multirow{7}{*}{$\begin{array}{l}\text { Late } \\
80 \mathrm{~s}\end{array}$} & & \multicolumn{4}{|c|}{ With scaling factor $(\xi)$} \\
\hline & & $\mathbf{F H}=1$ & $\mathbf{F H}=\mathbf{5}$ & $\mathbf{F H}=\mathbf{1 0}$ & $\mathbf{F H}=\mathbf{2 0}$ \\
\hline & $\beta_{1}$ & 5.0957 & 1.9226 & 0.6811 & -0.3550 \\
\hline & $\mathbf{t}_{0}$ & 4.0821 & 3.1092 & 1.0041 & -0.3116 \\
\hline & $\mathbf{t}_{1}$ & 3.2810 & 1.4920 & -0.4702 & -1.1892 \\
\hline & $\beta_{0}$ & 0.0008 & 0.0025 & 0.0033 & 0.0037 \\
\hline & $t_{0}$ & 3.2652 & 2.6235 & 1.6419 & 0.7001 \\
\hline \multirow{7}{*}{$\begin{array}{c}\text { Early } \\
90 \mathrm{~s}\end{array}$} & & \multicolumn{4}{|c|}{ With scaling factor $(\xi)$} \\
\hline & & $\mathbf{F H}=1$ & $\mathbf{F H}=5$ & $\mathbf{F H}=10$ & $\mathrm{FH}=\mathbf{2 0}$ \\
\hline & $\beta_{1}$ & 7.9997 & 3.2541 & 2.8907 & 2.6369 \\
\hline & $\mathbf{t}_{\mathbf{0}}$ & 5.4827 & 3.9685 & 2.4737 & 1.7265 \\
\hline & $t_{1}$ & 4.7974 & 2.7489 & 1.6180 & 1.0718 \\
\hline & $\beta_{0}$ & 0.0007 & 0.0006 & 0.0011 & 0.0019 \\
\hline & $\mathbf{t}_{0}$ & 2.8121 & 0.7418 & 0.7604 & 0.6986 \\
\hline \multirow{7}{*}{$\begin{array}{r}\text { Late } \\
90 \mathrm{~s}\end{array}$} & & \multicolumn{4}{|c|}{ With scaling factor $(\xi)$} \\
\hline & & $\mathbf{F H}=1$ & $\mathbf{F H}=5$ & $\mathbf{F H}=10$ & $\mathbf{F H}=20$ \\
\hline & $\beta_{1}$ & 6.6677 & 2.7010 & 1.2668 & 0.9636 \\
\hline & $\mathbf{t}_{0}$ & 4.8182 & 3.4450 & 1.7902 & 1.3222 \\
\hline & $\mathbf{t}_{1}$ & 4.0956 & 2.1695 & 0.3770 & -0.0499 \\
\hline & $\beta_{0}$ & 0.0001 & 0.0004 & 0.0005 & 0.0009 \\
\hline & $\mathbf{t}_{\mathbf{0}}$ & 0.9682 & 0.7729 & 0.4696 & 0.4350 \\
\hline
\end{tabular}

\begin{tabular}{|c|c|c|c|c|c|}
\hline \multicolumn{6}{|c|}{$\begin{array}{c}\text { Panel B. German Mark Regression of Currency } \\
\text { Depreciation on Futures - Spot Spread }\end{array}$} \\
\hline \multirow{7}{*}{$\begin{array}{c}\text { Early } \\
80 \mathrm{~s}\end{array}$} & & \multicolumn{4}{|c|}{ With scaling factor $(\xi)$} \\
\hline & & $\mathbf{F H}=1$ & FH=5 & $\mathrm{FH}=10$ & FH=20 \\
\hline & $\beta_{1}$ & 10.2489 & 3.2385 & 1.9692 & -0.1833 \\
\hline & $\mathbf{t}_{\mathbf{0}}$ & 7.3757 & 7.2979 & 4.1597 & -0.2475 \\
\hline & $\mathbf{t}_{1}$ & 6.6560 & 5.0444 & 2.0473 & -1.5978 \\
\hline & $\beta_{0}$ & -0.0011 & -0.0018 & -0.0019 & 0.0026 \\
\hline & $\mathbf{t}_{0}$ & -4.6234 & -1.8361 & -0.9117 & 0.5938 \\
\hline \multirow{7}{*}{$\begin{array}{l}\text { Late } \\
\text { 80s }\end{array}$} & & \multicolumn{4}{|c|}{ With scaling factor $(\xi)$} \\
\hline & & $\mathbf{F H}=1$ & FH=5 & $\mathbf{F H}=10$ & FH=20 \\
\hline & $\beta_{1}$ & 6.2746 & 2.8202 & 1.5642 & 0.9308 \\
\hline & $\mathbf{t}_{0}$ & 5.5053 & 5.7315 & 2.1709 & 0.7381 \\
\hline & $\mathbf{t}_{1}$ & 4.6279 & 3.6992 & 0.7830 & -0.0549 \\
\hline & $\beta_{0}$ & -0.0002 & 0.0000 & 0.0006 & 0.0021 \\
\hline & $\mathbf{t}_{0}$ & -1.2250 & 0.0163 & 0.3481 & 0.4936 \\
\hline \multirow{7}{*}{$\begin{array}{c}\text { Early } \\
90 \mathrm{~s}\end{array}$} & & \multicolumn{4}{|c|}{ With scaling factor $(\xi)$} \\
\hline & & FH=1 & FH=5 & FH=10 & $\mathrm{FH}=20$ \\
\hline & $\beta_{1}$ & 8.7907 & 2.5269 & 1.5347 & 1.0445 \\
\hline & $\mathbf{t}_{0}$ & 8.9638 & 4.0656 & 1.8673 & 1.0145 \\
\hline & $\mathbf{t}_{1}$ & 7.9441 & 2.4567 & 0.6506 & 0.0432 \\
\hline & $\beta_{0}$ & 0.0007 & 0.0014 & 0.0021 & 0.0035 \\
\hline & $\mathbf{t}_{0}$ & 3.5964 & 1.6114 & 1.2964 & 1.0994 \\
\hline \multirow{7}{*}{$\begin{array}{c}\text { Late } \\
90 \mathrm{~s}\end{array}$} & & \multicolumn{4}{|c|}{ With scaling factor $(\xi)$} \\
\hline & & $\mathbf{F H}=1$ & FH=5 & $F H=10$ & $\mathrm{FH}=20$ \\
\hline & $\beta_{1}$ & 6.1319 & 4.3679 & 2.8579 & 1.9693 \\
\hline & $\mathbf{t}_{\mathbf{0}}$ & 4.7369 & 5.6753 & 4.0749 & 2.4062 \\
\hline & $t_{1}$ & 3.9644 & 4.3759 & 2.6491 & 1.1844 \\
\hline & $\beta_{0}$ & -0.0009 & -0.0036 & -0.0059 & -0.0105 \\
\hline & $\mathbf{t}_{0}$ & -4.5245 & -4.6088 & -3.9218 & -3.2983 \\
\hline
\end{tabular}


Table 4 (Cont'd)

\begin{tabular}{|c|c|c|c|c|c|}
\hline \multicolumn{6}{|c|}{$\begin{array}{c}\text { Panel C. Japanese Yen Regression of Currency } \\
\text { Depreciation on Futures - Spot Spread }\end{array}$} \\
\hline \multirow{7}{*}{$\begin{array}{c}\text { Early } \\
80 \mathrm{~s}\end{array}$} & & \multicolumn{4}{|c|}{ With scaling factor $(\xi)$} \\
\hline & & $\mathbf{F H}=1$ & $\mathbf{F H}=5$ & $\mathrm{FH}=10$ & $\mathrm{FH}=\mathbf{2 0}$ \\
\hline & $\beta_{1}$ & 5.8162 & 1.8704 & 0.3570 & -2.1789 \\
\hline & $\mathbf{t}_{0}$ & 3.4663 & 3.6563 & 0.5033 & -2.0892 \\
\hline & $\mathbf{t}_{1}$ & 2.8703 & 1.7015 & -0.9068 & -3.0480 \\
\hline & $\beta_{0}$ & -0.0004 & 0.0002 & 0.0022 & 0.0112 \\
\hline & $\mathbf{t}_{0}$ & -1.7660 & 0.1962 & 1.0766 & 2.4403 \\
\hline \multirow{7}{*}{$\begin{array}{c}\text { Late } \\
80 \mathrm{~s}\end{array}$} & & \multicolumn{4}{|c|}{ With scaling factor $(\xi)$} \\
\hline & & $\mathbf{F H}=1$ & $\mathbf{F H}=5$ & $\mathrm{FH}=10$ & $\mathbf{F H}=20$ \\
\hline & $\beta_{1}$ & 5.4313 & 2.8719 & 1.3186 & -0.0009 \\
\hline & $\mathbf{t}_{0}$ & 5.2885 & 4.5987 & 1.7422 & -0.0008 \\
\hline & $\mathbf{t}_{1}$ & 4.3148 & 2.9974 & 0.4209 & -0.9190 \\
\hline & $\beta_{0}$ & -0.0003 & -0.0004 & 0.0005 & 0.0031 \\
\hline & $\mathbf{t}_{0}$ & -1.4904 & -0.4434 & 0.2878 & 0.7836 \\
\hline \multirow{7}{*}{$\begin{array}{c}\text { Early } \\
90 \mathrm{~s}\end{array}$} & & \multicolumn{4}{|c|}{ With scaling factor $(\xi)$} \\
\hline & & $\mathbf{F H}=1$ & $\mathbf{F H}=5$ & $\mathrm{FH}=10$ & $\mathrm{FH}=\mathbf{2 0}$ \\
\hline & $\beta_{1}$ & 7.5597 & 0.8524 & -0.2118 & -1.6615 \\
\hline & $\mathbf{t}_{0}$ & 6.1739 & 1.2105 & -0.2657 & -1.3590 \\
\hline & $\mathbf{t}_{1}$ & 5.3572 & -0.2095 & -1.5202 & -2.1769 \\
\hline & $\overline{\beta_{0}}$ & -0.0003 & 0.0006 & 0.0019 & 0.0059 \\
\hline & $\mathbf{t}_{0}$ & -1.4792 & 0.7846 & 1.2560 & 1.8256 \\
\hline \multirow{7}{*}{$\begin{array}{r}\text { Late } \\
90 \mathrm{~s}\end{array}$} & & \multicolumn{4}{|c|}{ With scaling factor $(\xi)$} \\
\hline & & $\mathbf{F H}=1$ & FH=5 & $\mathrm{FH}=10$ & FH=20 \\
\hline & $\beta_{1}$ & 10.4661 & 5.6752 & 2.9205 & 2.7599 \\
\hline & $\mathbf{t}_{\mathbf{0}}$ & 5.4235 & 4.0019 & 2.9817 & 3.2025 \\
\hline & $\mathbf{t}_{1}$ & 4.9053 & 3.2968 & 1.9607 & 2.0421 \\
\hline & $\beta_{0}$ & -0.0021 & -0.0061 & -0.0070 & -0.0134 \\
\hline & $\mathbf{t}_{0}$ & -4.9733 & -4.0301 & -2.7563 & -2.4047 \\
\hline
\end{tabular}

\begin{tabular}{|c|c|c|c|c|c|}
\hline \multicolumn{6}{|c|}{$\begin{array}{c}\text { Panel D. Swiss Franc Regression of Currency } \\
\text { Depreciation on Futures - Spot Spread }\end{array}$} \\
\hline \multirow{7}{*}{$\begin{array}{c}\text { Early } \\
80 \mathrm{~s}\end{array}$} & & \multicolumn{4}{|c|}{ With scaling factor $(\xi)$} \\
\hline & & $\mathbf{F H}=1$ & FH=5 & FH=10 & $\mathbf{F H}=20$ \\
\hline & $\beta_{1}$ & 8.9950 & 2.8670 & 1.6258 & -0.8900 \\
\hline & $\mathbf{t}_{0}$ & 6.2383 & 5.7624 & 3.1645 & -1.2811 \\
\hline & $\mathbf{t}_{1}$ & 5.5448 & 3.7525 & 1.2180 & -2.7206 \\
\hline & $\beta_{0}$ & -0.0016 & -0.0031 & -0.0037 & 0.0036 \\
\hline & $\mathbf{t}_{0}$ & -5.3851 & -2.6852 & -1.4406 & 0.6218 \\
\hline \multirow{7}{*}{$\begin{array}{c}\text { Late } \\
80 \mathrm{~s}\end{array}$} & & \multicolumn{4}{|c|}{ With scaling factor $(\xi)$} \\
\hline & & $\mathbf{F H}=1$ & $\mathbf{F H}=5$ & $\mathbf{F H}=\mathbf{1 0}$ & $\mathbf{F H}=\mathbf{2 0}$ \\
\hline & $\beta_{1}$ & 5.8704 & 1.9060 & 0.7586 & -0.5271 \\
\hline & $\mathbf{t}_{0}$ & 5.3770 & 4.0126 & 1.3361 & -0.6372 \\
\hline & $\mathbf{t}_{1}$ & 4.4610 & 1.9074 & -0.4251 & -1.8459 \\
\hline & $\beta_{0}$ & -0.0002 & 0.0011 & 0.0030 & 0.0081 \\
\hline & $\mathbf{t}_{0}$ & -0.7041 & 1.1077 & 1.5523 & 2.0742 \\
\hline \multirow{7}{*}{$\begin{array}{c}\text { Early } \\
90 \mathrm{~s}\end{array}$} & & \multicolumn{4}{|c|}{ With scaling factor $(\xi)$} \\
\hline & & $\mathbf{F H}=1$ & FH=5 & FH $=10$ & FH $=20$ \\
\hline & $\beta_{1}$ & 9.7752 & 3.6371 & 2.4320 & 1.9226 \\
\hline & $\mathbf{t}_{0}$ & 9.1342 & 5.5216 & 2.7831 & 1.3894 \\
\hline & $\mathbf{t}_{1}$ & 8.1998 & 4.0035 & 1.6387 & 0.6668 \\
\hline & $\beta_{0}$ & 0.0007 & 0.0013 & 0.0019 & 0.0036 \\
\hline & $\mathbf{t}_{0}$ & 2.6796 & 1.2754 & 0.9361 & 0.8436 \\
\hline \multirow{7}{*}{$\begin{array}{r}\text { Late } \\
90 \mathrm{~s}\end{array}$} & & \multicolumn{4}{|c|}{ With scaling factor $(\xi)$} \\
\hline & & $\mathbf{F H}=1$ & $\mathbf{F H}=5$ & $\mathbf{F H}=10$ & $\mathbf{F H}=20$ \\
\hline & $\beta_{1}$ & 6.7589 & 3.7237 & 1.6242 & 1.0040 \\
\hline & $\mathbf{t}_{\mathbf{0}}$ & 6.4062 & 5.3781 & 2.5634 & 1.7265 \\
\hline & $\mathbf{t}_{1}$ & 5.4584 & 3.9338 & 0.9852 & 0.0070 \\
\hline & $\beta_{0}$ & -0.0013 & -0.0040 & -0.0049 & -0.0081 \\
\hline & $\mathbf{t}_{\mathbf{0}}$ & -5.5090 & -4.4746 & -2.7223 & -2.0712 \\
\hline
\end{tabular}


Table 5: Summary of 4 Sub-samples for Market Efficiency and FPP across Currencies for Different Forecast Horizons

Regression equation: $s_{t+F H}-s_{t}=\beta_{0}+\beta_{1}\left(\xi_{t}\left(f_{t}-s_{t}\right)\right)+v 2_{t+F H}$,

where $s$ is the log of spot price, $f$ is $\log$ of futures price of the currency. The entire sample period of each currency is split into four parts. Estimates and t-values for each sub period of each currency are provided below. FH is the forecast horizon in number of trading days. $t_{0}$ is the $t$-value of the parameter measuring the significance of its difference from 0 ; $t_{1}$ is the $t$-value of the para-

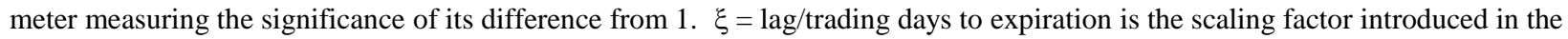
second set of regressions. BP: British pound, DM: German mark, JY: Japanese yen, SF: Swiss franc. Euro results are not reported since the whole sample period for the Euro consists only of a few recent years.

P1 through P4 represent each of the four sub sample periods for each currency. For BP and SF they are 1982 to mid 1986 , to 1991, to end of 1995, and to 2000; for DM and JY, the sub sample periods cover 1982 to late 1986, to mid 1991 , to 1996 and to 2001.

The numbers in the table are obtained by adding across all currencies, 1 representing the significantly bigger slope coefficients with respect to the threshold of one; 0 representing the insignificant slope coefficients, and -1 significantly less than one slope coefficients, respectively. The 'Absolute Sum' column is the sum of the absolute values of the numbers for each row. The efficiency measure in the table is obtained by adding the absolute values on the column and subtracting the total from the maximum possible value of 16. The higher this result the more efficient the market given the forecast horizon.

The last column is about the Forward Premium Puzzle (FPP) phenomenon. The negative significant slope coefficients indicate existence of the puzzle. The significance of the coefficients is determined at $5 \%$ level.

\begin{tabular}{|c|c|c|c|c|c|c|}
\hline ALL & FH1 & FH5 & FH10 & FH20 & Absolute Sum & FPP (FH20) \\
\hline P1 & 3 & 2 & 1 & -3 & 9 & -3 \\
\hline P2 & 4 & 3 & 0 & -1 & 8 & -1 \\
\hline P3 & 4 & 3 & 0 & -1 & 8 & -1 \\
\hline P4 & 4 & 4 & 2 & 1 & 11 & 1 \\
\hline $\begin{array}{c}\text { Efficiency } \\
\text { Measure }\end{array}$ & 1 & 4 & 13 & 10 & & \\
\hline
\end{tabular}


Table 6: Currency Change vs. Futures Spread Relation for Different Maturity Groups

Regression results of $s(T)-s(t)=\beta_{0}+\beta_{1}(f(t)-s(t))$. For each currency data is split into three parts based on the difference between the expiration date of the futures contract and current date. First group has these differences between 1 day to 1 -month. The second group is for 1-month to 2-months, and the last 2 months to 3 months. Regression coefficients and t-values are provided below. Newey-West regressions have been used.

$\mathrm{s}$ is $\log$ of spot price, $\mathrm{f}$ is $\log$ of futures price of the currency, $\mathrm{T}$ is the expiration date of the futures contract. Whole indicates the entire sample is taken, Early and Late are the sub-periods corresponding to 2-period partition. Finally, the entire sample period of each currency is split into four parts. Estimates and $t$-values for each sub period of each currency are provided below. $t_{0}$ is the $\mathrm{t}$-value of the parameter measuring the significance of its difference from $0 ; \mathrm{t}_{1}$ is the $\mathrm{t}$-value of the parameter measuring the significance of its difference from 1. BP: British pound, DM: German mark, JY: Japanese yen, SF: Swiss franc, EC: Euro. Euro results are provided only for the whole period since it consists only of a few recent years.

P1 through P4 represent each of the four sub sample periods for each currency. For BP and SF they are 1982 to mid 1986 , to 1991, to end of 1995, and to 2000; for DM and JY, the sub sample periods cover 1982 to late 1986, to mid 1991 , to 1996 and to 2001. 5\% significance levels are used for interpretation of the results.

\begin{tabular}{|c|c|c|c|c|c|c|c|c|c|c|c|c|c|}
\hline & & $\begin{array}{c}\text { BP } \\
\text { 1d-1m }\end{array}$ & $\begin{array}{c}\text { BP } \\
1 \mathrm{~m}-2 \mathrm{~m}\end{array}$ & $\begin{array}{c}\text { BP } \\
2 \mathrm{~m}-3 \mathrm{~m}\end{array}$ & $\begin{array}{c}\text { DM } \\
\text { 1d-1m }\end{array}$ & $\begin{array}{c}\text { DM } \\
1 \mathrm{~m}-2 \mathrm{~m}\end{array}$ & $\begin{array}{c}\text { DM } \\
2 \mathrm{~m}-3 \mathrm{~m}\end{array}$ & $\begin{array}{c}\text { JY } \\
\text { 1d-1m }\end{array}$ & $\begin{array}{c}\text { JY } \\
\text { 1m-2m }\end{array}$ & $\begin{array}{c}J Y \\
2 m-3 m\end{array}$ & $\begin{array}{c}\text { SF } \\
\text { 1d-1m }\end{array}$ & $\begin{array}{c}\text { SF } \\
1 \mathrm{~m}-2 \mathrm{~m}\end{array}$ & $\begin{array}{c}\text { SF } \\
2 m-3 m\end{array}$ \\
\hline \multirow{3}{*}{$\begin{array}{l}\text { Whole } \\
\text { Sample }\end{array}$} & $\beta_{1}$ & 0.339 & 0.207 & -0.327 & 0.794 & -0.021 & 0.088 & 0.863 & -0.192 & -1.039 & 0.636 & -0.313 & -0.438 \\
\hline & $\mathbf{t}_{0}$ & 1.174 & 0.845 & -1.222 & 4.549 & -0.086 & 0.361 & 4.321 & -0.581 & -3.680 & 3.657 & -1.292 & -1.685 \\
\hline & $t_{1}$ & -2.287 & -3.231 & -4.957 & -1.180 & -4.197 & -3.739 & -0.684 & -3.607 & -7.223 & -2.096 & -5.421 & -5.534 \\
\hline \multirow{3}{*}{$80 \mathrm{~s}$} & $\beta_{1}$ & 0.113 & -0.758 & -1.937 & 0.887 & 0.166 & -0.341 & 0.625 & -0.433 & -0.966 & 0.461 & -0.498 & -1.624 \\
\hline & $\mathbf{t}_{0}$ & 0.572 & -2.859 & -7.082 & 4.304 & 0.472 & -0.786 & 2.714 & -0.957 & -2.496 & 2.507 & -1.806 & -4.250 \\
\hline & $\mathbf{t}_{\mathbf{1}}$ & -4.511 & -6.629 & -10.739 & -0.549 & -2.369 & -3.096 & -1.629 & -3.165 & -5.080 & -2.929 & -5.434 & -6.867 \\
\hline \multirow{3}{*}{ 90s } & $\beta_{1}$ & 1.984 & 1.469 & 1.761 & 0.799 & -0.187 & -0.347 & 1.063 & -0.046 & -1.020 & 1.109 & 0.120 & 0.067 \\
\hline & $\mathbf{t}_{\mathbf{0}}$ & 3.929 & 3.544 & 3.778 & 2.601 & -0.511 & -1.047 & 3.072 & -0.098 & -2.620 & 3.191 & 0.300 & 0.169 \\
\hline & $\mathbf{t}_{1}$ & 1.948 & 1.132 & 1.633 & -0.655 & -3.246 & -4.067 & 0.182 & -2.241 & -5.187 & 0.314 & -2.204 & -2.357 \\
\hline \multirow{3}{*}{$\begin{array}{c}\text { Early } \\
\text { 80s }\end{array}$} & $\beta_{1}$ & -0.051 & -1.096 & -1.924 & 0.650 & -0.500 & -1.065 & 0.312 & -2.111 & -2.644 & 0.485 & -0.865 & -0.717 \\
\hline & $\mathbf{t}_{\mathbf{0}}$ & -0.367 & -3.302 & -5.307 & 2.024 & -1.299 & -1.906 & 0.893 & -4.292 & -4.645 & 1.687 & -2.214 & -1.306 \\
\hline & $\mathbf{t}_{\mathbf{1}}$ & -7.555 & -6.313 & -8.065 & -1.090 & -3.899 & -3.697 & -1.973 & -6.325 & -6.402 & -1.794 & -4.774 & -3.126 \\
\hline \multirow{3}{*}{$\begin{array}{c}\text { Early } \\
90 \mathrm{~s}\end{array}$} & $\beta_{1}$ & 0.973 & 0.792 & -0.653 & 1.148 & 0.895 & 0.663 & 0.994 & 1.044 & -0.001 & 0.555 & 0.342 & -1.607 \\
\hline & $\mathbf{t}_{\mathbf{0}}$ & 3.719 & 1.545 & -1.169 & 4.709 & 1.660 & 1.023 & 3.612 & 1.519 & -0.001 & 2.621 & 0.881 & -2.884 \\
\hline & $\mathbf{t}_{\mathbf{1}}$ & -0.103 & -0.405 & -2.960 & 0.606 & -0.194 & -0.519 & -0.023 & 0.064 & -1.520 & -2.102 & -1.695 & -4.679 \\
\hline \multirow{3}{*}{$\begin{array}{c}\text { Early } \\
90 \mathrm{~s}\end{array}$} & $\beta_{1}$ & 2.574 & 1.909 & 2.608 & 1.342 & 0.893 & 0.519 & 0.733 & -1.470 & -2.130 & 1.866 & 2.025 & 2.294 \\
\hline & $\mathbf{t}_{\mathbf{0}}$ & 3.944 & 3.558 & 5.181 & 3.199 & 1.765 & 1.125 & 1.889 & -2.001 & -2.938 & 3.854 & 2.715 & 2.686 \\
\hline & $\mathbf{t}_{\mathbf{1}}$ & 2.412 & 1.694 & 3.194 & 0.815 & -0.211 & -1.041 & -0.689 & -3.363 & -4.317 & 1.788 & 1.374 & 1.515 \\
\hline \multirow{3}{*}{$\begin{array}{c}\text { Late } \\
90 \mathrm{~s}\end{array}$} & $\beta_{1}$ & -0.241 & 0.390 & -0.534 & 0.722 & 1.297 & 1.050 & 1.172 & 1.927 & 0.259 & 0.252 & 0.237 & 1.056 \\
\hline & $\mathbf{t}_{\mathbf{0}}$ & -0.712 & & -1.080 & 1.732 & 2.158 & 1.960 & 1.966 & 2.551 & 0.317 & 0.596 & 0.487 & 2.216 \\
\hline & $\mathbf{t}_{\mathbf{1}}$ & -3.669 & -1.591 & -3.104 & -0.667 & 0.494 & 0.093 & 0.289 & 1.227 & -0.910 & -1.765 & -1.567 & 0.118 \\
\hline
\end{tabular}


Table 7: Summary of Different Maturity Ranges across Currencies for Efficiency and FPP

Regression equation: $s(T)-s(t)=\beta_{0}+\beta_{1}(f(t)-s(t))$.

where $s$ is the $\log$ of spot price, $f$ is $\log$ of futures price of the currency. The entire sample period of each currency is split into four parts. BP: British pound, DM: German mark, JY: Japanese yen, SF: Swiss franc. Euro results are not reported since the whole sample period for the Euro consists only of a few recent years.

P1 through P4 represent each of the four sub sample periods for each currency. For BP and SF they are 1982 to mid 1986 , to 1991, to end of 1995, and to 2000; for DM and JY, the sub sample periods cover 1982 to late 1986, to mid 1991 , to 1996 and to 2001.

$1 \mathrm{~d}-1 \mathrm{~m}$ represents observations with maturity up to 1 -month, $1 \mathrm{~m}-2 \mathrm{~m}$ of maturities between 1 -month and 2 -months, $2 \mathrm{~m}$ - $3 \mathrm{~m}$ of maturities between 2-months and 3-months.

The numbers in the table are obtained by adding across all currencies, 1 representing the significantly bigger slope coefficients with respect to the threshold of one; 0 representing the insignificant slope coefficients, and -1 significantly less than one slope coefficients, respectively. The 'Absolute Sum' column is the sum of the absolute values of the numbers for each row. The efficiency measure in the table is obtained by adding the absolute values on the column and subtracting the total from the maximum possible value of 16. The higher this result the more efficient the market given the forecast horizon.

The last three columns are about the Forward Premium Puzzle (FPP) phenomenon. The negative significant slope coefficients indicates existence of the puzzle. The significance of the coefficients is determined at $5 \%$ level.

\begin{tabular}{|c|c|c|c|c|c|c|c|}
\hline ALL & 1d-1m & $1 \mathrm{~m}-2 \mathrm{~m}$ & $2 m-3 m$ & Absolute Sum & $\begin{array}{c}\text { FPP } \\
\text { 1d-1m }\end{array}$ & $\begin{array}{c}\text { FPP } \\
1 \mathrm{~m}-2 \mathrm{~m}\end{array}$ & $\begin{array}{c}\text { FPP } \\
2 \mathrm{~m}-3 \mathrm{~m} \\
\end{array}$ \\
\hline P1 & -3 & -4 & -4 & 11 & 0 & 3 & 2 \\
\hline $\mathbf{P 2}$ & -1 & 0 & -2 & 3 & 0 & 0 & 1 \\
\hline P3 & 1 & -1 & $1-1$ & 4 & 0 & 1 & 1 \\
\hline P4 & -1 & 0 & -1 & 21 & 0 & 0 & 0 \\
\hline $\begin{array}{c}\text { Efficiency } \\
\text { Measure }\end{array}$ & 10 & 11 & 7 & & & & \\
\hline
\end{tabular}


Figure 1: Volume of Trade over the Life of a Single Contract - BP December 1991 Futures

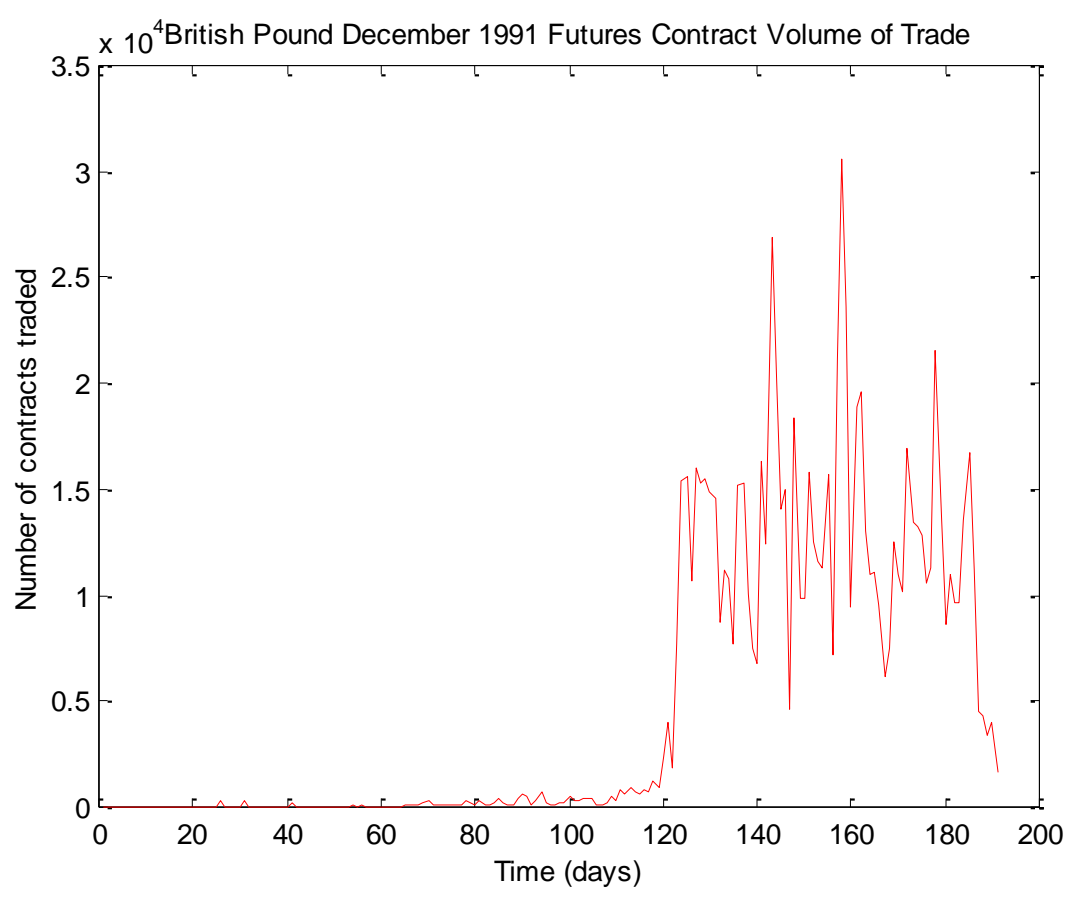

Figure 2: Daily Volume of Trade for Currency Futures
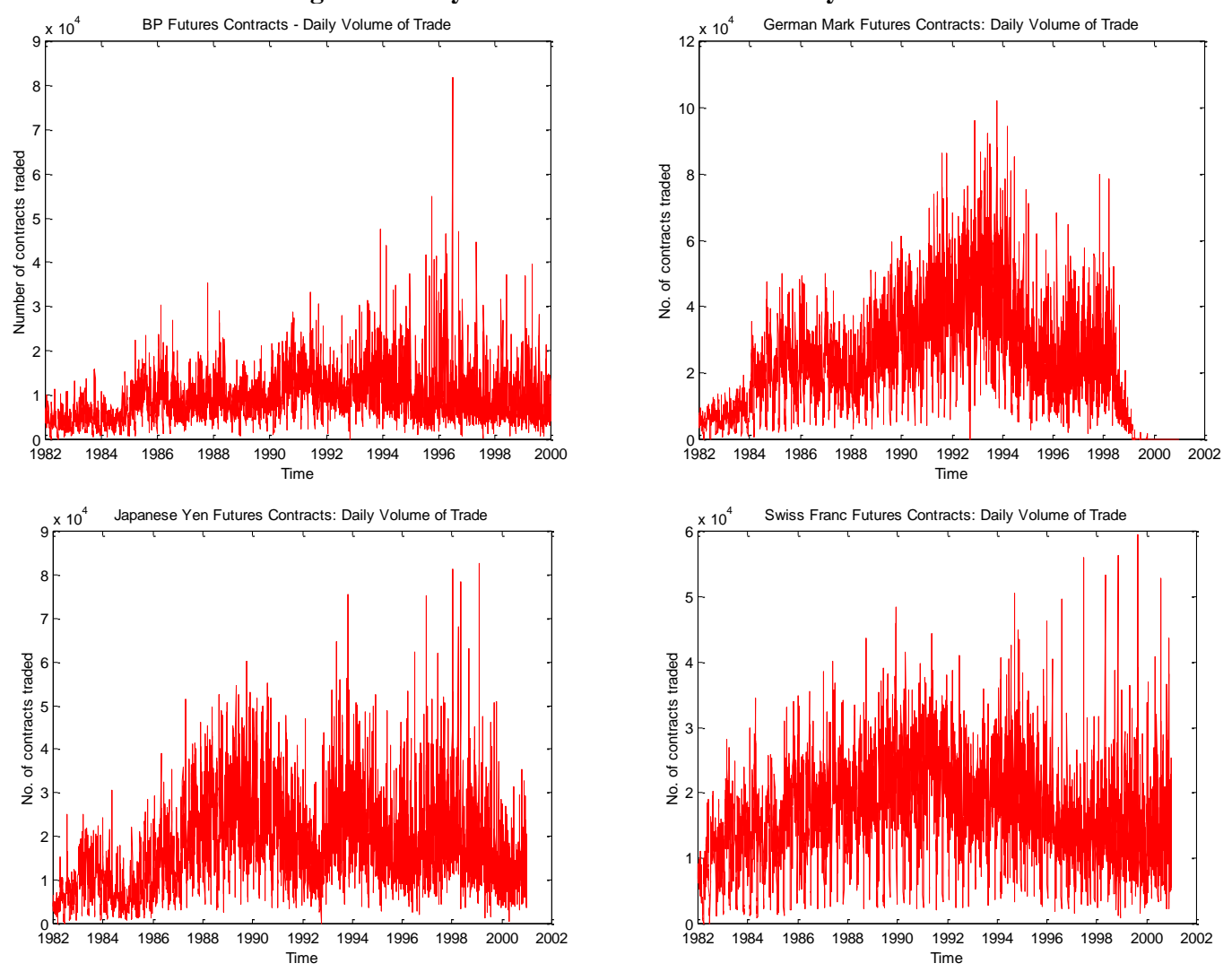
Notes 